\title{
Impacts of different characterizations of large-scale background on simulated regional-scale ozone over the continental United States
}

\author{
Christian Hogrefe ${ }^{1}$, Peng Liu ${ }^{2}$, George Pouliot ${ }^{1}$, Rohit Mathur ${ }^{1}$, Shawn Roselle ${ }^{1}$, Johannes Flemming ${ }^{3}$, \\ Meiyun Lin ${ }^{4,5}$, and Rokjin J. Park ${ }^{6}$ \\ ${ }^{1}$ Computational Exposure Division, National Exposure Research Laboratory, US Environmental Protection Agency, \\ Research Triangle Park, NC, USA \\ ${ }^{2}$ National Research Council Fellow at National Exposure Research Laboratory, US Environmental Protection Agency, \\ Research Triangle Park, NC, USA \\ ${ }^{3}$ European Centre for Medium-Range Weather Forecasts, Reading, UK \\ ${ }^{4}$ Atmospheric and Oceanic Sciences, Princeton University, Princeton, NJ, USA \\ ${ }^{5}$ NOAA Geophysical Fluid Dynamics Laboratory, Princeton, NJ, USA \\ ${ }^{6}$ School of Earth and Environmental Sciences, Seoul National University, Seoul, South Korea
}

Correspondence: Christian Hogrefe (hogrefe.christian@epa.gov)

Received: 19 July 2017 - Discussion started: 8 August 2017

Revised: 19 January 2018 - Accepted: 13 February 2018 - Published: 16 March 2018

\begin{abstract}
This study analyzes simulated regional-scale ozone burdens both near the surface and aloft, estimates process contributions to these burdens, and calculates the sensitivity of the simulated regional-scale ozone burden to several key model inputs with a particular emphasis on boundary conditions derived from hemispheric or global-scale models. The Community Multiscale Air Quality (CMAQ) model simulations supporting this analysis were performed over the continental US for the year 2010 within the context of the Air Quality Model Evaluation International Initiative (AQMEII) and Task Force on Hemispheric Transport of Air Pollution (TF-HTAP) activities. CMAQ process analysis (PA) results highlight the dominant role of horizontal and vertical advection on the ozone burden in the mid-to-upper troposphere and lower stratosphere. Vertical mixing, including mixing by convective clouds, couples fluctuations in freetropospheric ozone to ozone in lower layers. Hypothetical bounding scenarios were performed to quantify the effects of emissions, boundary conditions, and ozone dry deposition on the simulated ozone burden. Analysis of these simulations confirms that the characterization of ozone outside the regional-scale modeling domain can have a profound impact on simulated regional-scale ozone. This was further investigated by using data from four hemispheric or global mod-
\end{abstract}

eling systems (Chemistry - Integrated Forecasting Model (C-IFS), CMAQ extended for hemispheric applications (HCMAQ), the Goddard Earth Observing System model coupled to chemistry (GEOS-Chem), and AM3) to derive alternate boundary conditions for the regional-scale CMAQ simulations. The regional-scale CMAQ simulations using these four different boundary conditions showed that the largest ozone abundance in the upper layers was simulated when using boundary conditions from GEOS-Chem, followed by the simulations using C-IFS, AM3, and H-CMAQ boundary conditions, consistent with the analysis of the ozone fields from the global models along the CMAQ boundaries. Using boundary conditions from AM3 yielded higher springtime ozone columns burdens in the middle and lower troposphere compared to boundary conditions from the other models. For surface ozone, the differences between the AM3driven CMAQ simulations and the CMAQ simulations driven by other large-scale models are especially pronounced during spring and winter where they can reach more than $10 \mathrm{ppb}$ for seasonal mean ozone mixing ratios and as much as $15 \mathrm{ppb}$ for domain-averaged daily maximum $8 \mathrm{~h}$ average ozone on individual days. In contrast, the differences between the C-IFS-, GEOS-Chem-, and H-CMAQ-driven regional-scale CMAQ simulations are typically smaller. Comparing simulated sur- 
face ozone mixing ratios to observations and computing seasonal and regional model performance statistics revealed that boundary conditions can have a substantial impact on model performance. Further analysis showed that boundary conditions can affect model performance across the entire range of the observed distribution, although the impacts tend to be lower during summer and for the very highest observed percentiles. The results are discussed in the context of future model development and analysis opportunities.

\section{Introduction}

Regional-scale air quality modeling systems such as the Community Multiscale Air Quality (CMAQ) model (Byun and Schere, 2006), the Comprehensive Air Quality Model with Extensions (CAMx) (Environ, 2014), the Weather Research and Forecasting model coupled to Chemistry (WRFChem) (Chapman et al., 2009), and CHIMERE (Vautard et al., 2001) are routinely used for air quality forecasting and planning applications. Many of these models trace their heritage to local-scale models developed to better understand and mitigate elevated ozone in highly polluted urban airsheds such as the Los Angeles basin (McRae and Seinfeld, 1983; Harley et al., 1993). As further research highlighted regional aspects of ozone pollution such as multi-state transport of ozone and its precursors (Eder et al., 1994; Vukovich, 1995; Schichtel and Husar, 2001), these urban-scale models were expanded to represent processes relevant to regionaland continental-scale air quality. Because of their origin in urban- and regional-scale air quality modeling and their primary application focus of simulating air quality as it relates to human health (i.e., air applications for air quality planning and forecasting), the performance of these modeling systems is often evaluated primarily at the surface against measurements from monitors in the vicinity of populated areas ( $\mathrm{Si}-$ mon et al., 2012; Appel et al., 2017).

The evaluation and intercomparison of regional-scale air quality models has been the central focus of the Air Quality Evaluation International Initiative (AQMEII) that was initiated in 2009 (Rao et al., 2011). Much of the initial work under AQMEII focused on operational model evaluation (Solazzo et al., 2012a, b; Im et al., 2015a, b) while there was an increasing emphasis on diagnostic evaluation in more recent analyses (Solazzo and Galmarini, 2016; Solazzo et al., 2017a, b). Some of these diagnostic analyses have pointed to external model inputs, in particular emissions and boundary conditions representing the larger-scale atmospheric background, as key sources of model error (Schere et al., 2012; Giordano et al., 2015; Solazzo et al., 2017a, b).

Somewhat in parallel to the increased development and use of regional-scale air quality models for air quality management and forecasting starting in the mid-to-late 1990s and early 2000s, there also was active development of global- scale chemistry-transport models such as the Goddard Earth Observing System model coupled to chemistry (GEOSChem) (Bey et al., 2001), the Model for Ozone and Related chemical Tracers (MOZART) (Horowitz et al., 2003; Emmons et al., 2010), and AM3 (Donner et al., 2011; Lin et al., 2012a) as well as on-line coupled weather-chemistry models such as the European Centre for Medium Range Weather Forecasts (ECMWF) Composition - Integrated Forecast System (C-IFS) model (Flemming et al., 2015). A primary use of such global models has been to better understand long-term trends and variability in tropospheric pollutant burdens and budgets, and to quantify intercontinental transport. Such research on intercontinental transport of air pollution (Jacob et al., 1999; Li et al., 2002; Holloway et al., 2003; Fiore et al., 2009; Reidmiller et al., 2009; Lin et al., 2015, 2017) led to the increasing recognition of surface ozone as a pollutant that is impacted by phenomena occurring on spatial scales ranging from local to global and temporal scales, and ranging from hours to decades. Much of this research either contributed to or was directly organized through the Task Force on Hemispheric Transport of Air Pollution (TFHTAP), resulting in a comprehensive assessment of the science underlying long-range pollutant transport (TF-HTAP, 2010). Model evaluation performed for such global models often has focused on remote, rural, and/or high-elevation sites since the grid resolution employed in these models is not expected to fully resolve more fine-scale physical and chemical processes that are important in areas of complex terrain, land-sea interfaces, or areas of large emission gradients.

The growing realization that regional-scale air quality models depend on inputs from global models to properly characterize large-scale pollutant fluctuations while global models may benefit from the experiences gained in modeling air quality at finer scales motivated the organization of coordinated global- and regional-scale modeling experiments under the umbrella of TF-HTAP (HTAP2) with contributions from the third phase of AQMEII (AQMEII3) as well as the MICS-Asia community, as detailed in Galmarini et al. (2017). In this study, we present the results of regionalscale CMAQ simulations over North America driven by different representations of large-scale atmospheric composition as simulated by large-scale models participating in TFHTAP. The study aims at quantifying simulated regionalscale ozone burdens both near the surface and aloft, estimating process contributions to these burdens, and calculating the sensitivity of the simulated regional-scale ozone burden to several key model inputs, in particular the global atmosphere as simulated by large-scale models and represented in CMAQ through the use of different boundary conditions. It should be noted at the outset that an intercomparison and evaluation of the various large-scale models are outside the scope of this study but are being pursued by other groups in the context of TF-HTAP. 


\section{Model simulations and observations}

The 2010 annual simulations analyzed in this study were performed with version 5.0.2 of the CMAQ model (Byun and Schere, 2006) using meteorological fields prepared with version 3.4 of the Weather Research and Forecasting (WRF) model (Skamarock and Klemp, 2007) and emission inputs described in Pouliot et al. (2015). The CMAQ simulations were performed with a horizontal grid spacing of $12 \mathrm{~km}$ over the continental US and used 35 vertical layers extending to $50 \mathrm{mb}$.

For the base case simulations (hereafter referred to as BASE), lateral chemical boundary conditions were prepared from global concentration fields simulated by C-IFS (Flemming et al., 2015). Meteorological and air quality fields from these BASE simulations were evaluated against observations by Solazzo et al. (2017a, b). The BASE simulations also included the tracking of contributions from different processes to ozone mixing ratios using the integrated process rate (IPR) process analysis (PA) approach (Jeffries and Tonnesen, 1994; Jang et al., 1995) as implemented in CMAQ (Byun and Ching, 1999).

To assess the maximum impacts of boundary conditions, anthropogenic emissions within the domain, and ozone dry deposition on simulated ozone mixing ratios, the BASE simulations were augmented by three annual bounding simulations. In the first of these bounding simulations (hereafter referred to as BC ZERO), lateral boundary conditions for all species were set to a time-invariant value of zero while all other settings were identical to BASE. In the second simulation (hereafter referred to as EM ZERO), all anthropogenic emissions as well as wildfire emissions within the domain were set to zero while all other settings were identical to BASE. For the third simulation (hereafter referred to as NO O3 DDEP), ozone dry deposition was set to zero while all other settings were identical to BASE.

Finally, to further investigate the effects of using chemical boundary conditions derived from different global or hemispheric models, three additional annual simulations were performed using concentrations derived from (1) CMAQ version 5.1 configured for hemispheric applications, hereafter referred to as H-CMAQ (Xing et al., 2015a, b; Mathur et al., 2017), (2) the GEOS-Chem model (Bey et al., 2001) version 9-01-03 which includes full tropospheric chemistry and a climatological representation of stratospheric sources and sinks, and (3) the AM3 model (Donner et al., 2011; Lin et al., 2012b, 2017) with coupled stratospheretroposphere chemistry. These simulations leveraged the coordinated AQMEII3/HTAP2 modeling experiments (Galmarini et al., 2017; Huang et al., 2017). In particular, all of these alternative global simulations providing boundary conditions (as well as the C-IFS simulations providing boundary conditions for BASE) utilized the same global anthropogenic emission inventory described in Janssens-Maenhout et al. (2015) that is consistent with the regional-scale inven- tory used in the CMAQ simulations and described by Pouliot et al. (2015). However, non-anthropogenic emissions were not harmonized across the global- and regional-scale simulations. As described in Flemming et al. (2015), the CIFS simulations used lightning emissions based on the parameterization introduced in Meijer et al. (2001), biogenic emissions calculated with version 2.1 of the Model of Emissions of Gases and Aerosols from Nature (MEGAN) (Guenther et al., 2006), and biomass burning emissions produced by the Global Fire Assimilation System (GFAS) version 1 (Kaiser et al., 2012). The H-CMAQ simulations used climatological biogenic and lightning emissions from the Global Emission Inventory Activity (GEIA) data set (Guenther et al., 1995; Price et al., 1997) and biomass burning emissions from version 4.2 of the Emission Database for Global Atmospheric Research (EDGAR) (European Commission, 2011). The GEOS-Chem simulations used lightning emissions based on the methodology described in Murray et al. (2012), biogenic emissions calculated with MEGAN version 2.1, and biomass burning from version 3 of the Global Fire Emissions Database (GFED) (Randerson et al., 2013; van der Werf et al., 2006). The AM3 simulations used lightning emissions based on the parameterization introduced in Horowitz et al. (2003), biogenic emissions calculated with MEGAN version 2.1, and biomass burning emissions from the Fire INventory from NCAR (FINN) (Wiedinmyer et al., 2011). The regional-scale CMAQ simulations did not include lightning emissions, calculated biogenic emissions using version 3.14 of the Biogenic Emission Inventory System (BEIS) (Pierce et al., 1998; Vukovich and Pierce, 2002; Schwede et al., 2005), and used 2010 wildfire emissions as described in Pouliot et al. (2015).

To create boundary conditions for the regional CMAQ simulations, outputs from the large-scale models were vertically interpolated and gas-phase and aerosol species were mapped to the CB05TUCL/Aero6 mechanism used by CMAQ. Previous studies deriving regional-scale boundary conditions from global-scale models noted the importance of maintaining sufficient vertical resolution in the upper troposphere and lower stratosphere in the regional model (Lin et al., 2009) and properly mapping chemical species between the modeling systems (Henderson et al., 2014). A list of the gas-phase species mapped between the large-scale models and CMAQ is shown in Table 1, and a depiction of the vertical layers used in the large-scale models and regional CMAQ simulations is provided in Fig. 1. Sulfate, nitrate, ammonium, and elemental and organic carbon aerosols were available from all large-scale models while CMAQ trace element aerosol concentrations were estimated from large-scale model dust and sea-salt concentrations except in the case of H-CMAQ which used the same aerosol mechanism as the regional-scale CMAQ simulations. CMAQ species not available from the large-scale models were obtained from the time-invariant CMAQ default profile (available at 
Table 1. Mapping of gas-phase species from C-IFS, H-CMAQ, GEOS-Chem, and AM3 to regional-scale CMAQ.

\begin{tabular}{|c|c|c|c|c|}
\hline $\begin{array}{l}\text { CMAQv5.0.2 } \\
\text { CB05-TUCL } \\
\text { Target species }\end{array}$ & C-IFS species & H-CMAQ species & GEOS-Chem species & AM3 species \\
\hline $\mathrm{O}_{3}$ & $\mathrm{O}_{3}$ & $\mathrm{O}_{3}$ & $\mathrm{O}_{x}-\mathrm{NO}_{x}$ & $\mathrm{O}_{3}$ \\
\hline $\mathrm{CO}$ & $\mathrm{CO}$ & $\mathrm{CO}$ & $\mathrm{CO}$ & $\mathrm{CO}$ \\
\hline FORM & $\mathrm{CH}_{2} \mathrm{O}$ & FORM & $\mathrm{CH}_{2} \mathrm{O}$ & \\
\hline NO & $\mathrm{NO}$ & $\mathrm{NO}$ & $\mathrm{NO}$ & $\mathrm{NO}$ \\
\hline $\mathrm{NO}_{2}$ & $\mathrm{NO}_{2}$ & $\mathrm{NO}_{2}$ & $\mathrm{NO}_{2}$ & $\mathrm{NO}_{2}$ \\
\hline $\mathrm{HNO}_{3}$ & $\mathrm{HNO}_{3}$ & $\mathrm{HNO}_{3}$ & $\mathrm{HNO}_{3}$ & $\mathrm{HNO}_{3}$ \\
\hline $\mathrm{N}_{2} \mathrm{O}_{5}$ & & $\mathrm{~N}_{2} \mathrm{O}_{5}$ & $\mathrm{~N}_{2} \mathrm{O}_{5}$ & \\
\hline PAN & PAN & PAN & PAN & PAN \\
\hline PANX & & PANX & PPN, PMN & \\
\hline $\mathrm{SO}_{2}$ & $\mathrm{SO}_{2}$ & $\mathrm{SO}_{2}$ & $\mathrm{SO}_{2}$ & $\mathrm{SO}_{2}$ \\
\hline PAR & $\begin{array}{l}\mathrm{PAR}, \mathrm{CH}_{3} \mathrm{COCH}_{3}, \\
\mathrm{C}_{3} \mathrm{H}_{8}\end{array}$ & PAR & $\begin{array}{l}\mathrm{C}_{3} \mathrm{H}_{8}, \text { ALK } 4 \text {, ACET, } \\
\text { MEK, BENZ }\end{array}$ & ACETONE, PROPANE \\
\hline ETHA & $\mathrm{C}_{2} \mathrm{H}_{6}$ & ETHA & $\mathrm{C}_{2} \mathrm{H}_{6}$ & $\mathrm{C}_{2} \mathrm{H}_{6}$ \\
\hline $\mathrm{MEOH}$ & $\mathrm{CH}_{3} \mathrm{OH}$ & MEOH & & \\
\hline ETOH & $\mathrm{C}_{2} \mathrm{H}_{5} \mathrm{OH}$ & ETOH & & \\
\hline ETH & $\mathrm{C}_{2} \mathrm{H}_{4}$ & ETH & & \\
\hline ALD2 & ALD2 & ALD2 & ALD2 & \\
\hline OLE & OLE & OLE & PRPE & \\
\hline ISOP & ISOP & ISOP & ISOP & \\
\hline ISPD & & ISPD & MACR, MVK & \\
\hline FACD & $\mathrm{HCOOH}$ & FACD & & \\
\hline MEPX & $\mathrm{CH} 3 \mathrm{OOH}$ & MEPX & MP & \\
\hline NTR & ONIT & $\begin{array}{l}\text { NTROH, NTRALK, } \\
\text { NTRCN, NTRCNOH, } \\
\text { NTRM, NTRI, NTRPX }\end{array}$ & R4N2 & \\
\hline PNA & & PNA & $\mathrm{HNO}_{4}$ & \\
\hline $\mathrm{H}_{2} \mathrm{O}_{2}$ & & $\mathrm{H}_{2} \mathrm{O}_{2}$ & $\mathrm{H}_{2} \mathrm{O}_{2}$ & \\
\hline IOLE & & IOLE & PRPE & \\
\hline TOL & & TOL & TOLU & \\
\hline XYL & & XYL & XYLE & \\
\hline BENZENE & & BENZENE & BENZ & \\
\hline
\end{tabular}

https://github.com/USEPA/CMAQ/blob/5.0.2/models/BCON /prof_data/cb05_ae6_aq/bc_profile_CB05.dat, last access: 10 January 2018). The sensitivity simulations with the three alternate sets of boundary conditions are hereafter referred to as BC H-CMAQ, BC GEOS-Chem, and BC AM3, respectively. For reference, a list of all simulations, their acronyms, and their configurations is provided in Table 2.

For the purpose of CMAQ evaluation, hourly observations of ozone were retrieved from the US Environmental Protection Agency (US EPA) Air Quality System (AQS) database and were used to calculate daily maximum $8 \mathrm{~h}$ average (MDA8) ozone values. In addition, Clean Air Status and Trends Network (CASTNET) hourly ozone observations were also obtained to evaluate the performance of both large-scale models and regional CMAQ at these mostly rural locations. Finally, ozonesonde observations at Trinidad Head (latitude $-124.16^{\circ} \mathrm{W}$, longitude $40.8^{\circ} \mathrm{N}$, elevation $20 \mathrm{~m}$ ), Edmonton (latitude $-114.1^{\circ} \mathrm{W}$, longitude $53.55^{\circ} \mathrm{N}$, elevation $766 \mathrm{~m}$ ), Churchill (latitude $-94.07^{\circ} \mathrm{W}$, longitude $58.75^{\circ} \mathrm{N}$, elevation $30 \mathrm{~m}$ ), Boulder (latitude $-105.2^{\circ} \mathrm{W}$, longitude $39.95^{\circ} \mathrm{N}$, elevation $1743 \mathrm{~m}$ ), Huntsville (latitude $-86.59^{\circ} \mathrm{W}$, longitude $35.28^{\circ} \mathrm{N}$, elevation $196 \mathrm{~m}$ ), and Wallops Island (latitude $-75.48^{\circ} \mathrm{W}$, longitude $37.9^{\circ} \mathrm{N}$, elevation $13 \mathrm{~m}$ ) were obtained from the National Oceanic and Atmospheric Administration (NOAA) Earth System Research Laboratory and the World Ozone and UV Data Center to evaluate upper air ozone simulated by the large-scale models and regional CMAQ. Model performance evaluation was performed both across the entire domain (1207 AQS monitors and 79 CASTNET monitors) and separately for five subregions that are characterized by differences in their proximity to the domain boundaries, elevation, and relative abundance of anthropogenic and biogenic emissions: Northwest (NW) (41 AQS monitors and 2 CASTNET monitors), Intermountain West (IMW) (53 AQS monitors and 7 CASTNET monitors), Midwest (MW) (195 AQS monitors and 13 CASTNET monitors), Southeast (SE) (166 AQS monitors and 13 CASTNET monitors), and Northeast (NE) (204 AQS monitors and 
Table 2. List of regional-scale CMAQ simulations.

\begin{tabular}{|c|c|c|c|}
\hline Acronym & $\begin{array}{l}\text { Lateral boundary } \\
\text { conditions }\end{array}$ & Emissions & CMAQ configuration \\
\hline BASE & C-IFS & Pouliot et al. (2015) & $\begin{array}{l}\text { Solazzo et al. (2017a) } \\
\text { Hogrefe et al. (2017) }\end{array}$ \\
\hline BC ZERO & Zero for all species & Pouliot et al. (2015) & $\begin{array}{l}\text { Solazzo et al. (2017a) } \\
\text { Hogrefe et al. (2017) }\end{array}$ \\
\hline EM ZERO & C-IFS & $\begin{array}{l}\text { Zero for anthropogenic and wildfire } \\
\text { emissions within the CMAQ mod- } \\
\text { eling domain }\end{array}$ & $\begin{array}{l}\text { Solazzo et al. (2017a) } \\
\text { Hogrefe et al. (2017) }\end{array}$ \\
\hline NO O3 DDEP & C-IFS & Pouliot et al. (2015) & $\begin{array}{l}\text { Solazzo et al. (2017a) } \\
\text { Hogrefe et al. (2017) } \\
\text { Modified to "turn off" ozone dry de- } \\
\text { position }\end{array}$ \\
\hline BC H-CMAQ & H-CMAQ & Pouliot et al. (2015) & $\begin{array}{l}\text { Solazzo et al. (2017a) } \\
\text { Hogrefe et al. (2017) }\end{array}$ \\
\hline BC GEOS-Chem & GEOS-Chem & Pouliot et al. (2015) & $\begin{array}{l}\text { Solazzo et al. (2017a) } \\
\text { Hogrefe et al. (2017) }\end{array}$ \\
\hline BC AM3 & AM3 & Pouliot et al. (2015) & $\begin{array}{l}\text { Solazzo et al. (2017a) } \\
\text { Hogrefe et al. (2017) }\end{array}$ \\
\hline
\end{tabular}

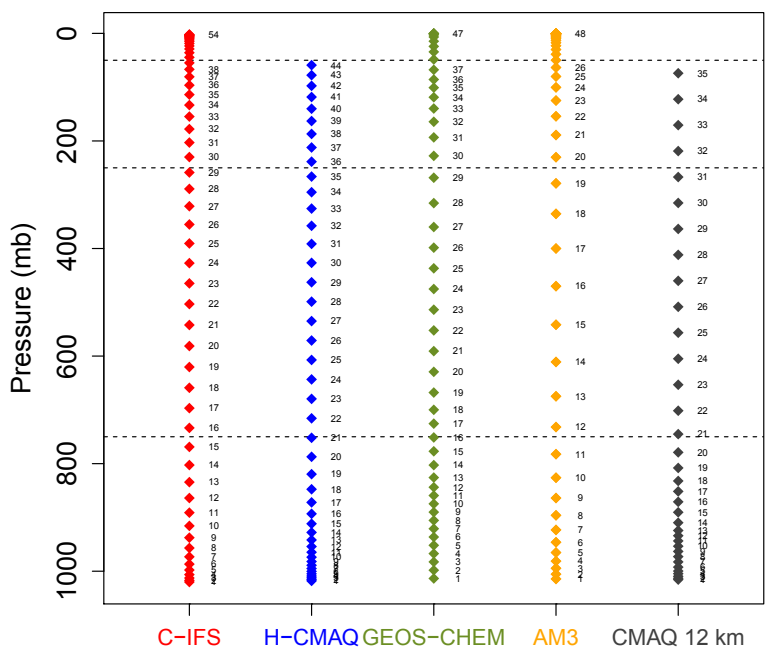

Figure 1. Depiction of the vertical levels used in the four different large-scale models and the regional CMAQ model analyzed in this study. The pressure values were extracted for a location near the southwestern corner of the $12 \mathrm{~km}$ CMAQ modeling domain and represent annual average values for 2010 at the midpoint of each vertical level. The dashed lines delineate the three pressure ranges (surface to $750,750-250$, and $250-50 \mathrm{mb}$ ) used for vertical integration in subsequent analyses.

15 CASTNET monitors). Note that these analysis subregions do not cover the entire modeling domain. For all comparisons of observations and model simulations presented in this study, data pairs were included in the computation of derived metrics, such as daytime averages (defined as average mixing ratios between 10:00 and 17:00 LT) or monthly averages, only when both observations and model simulations were available for a given hour. Furthermore, each monitored value was paired with the corresponding model value based on the model grid cell in which the monitor was located. In particular, multiple observations within the same grid cells were not averaged because the definition of the horizontal grids varied between all the simulations analyzed in this study. For seasonal analyses, winter was defined as December-February, spring was defined as March-May, summer was defined as June-August, and fall was defined as September-November. Figure 2 shows a map of the entire WRF/CMAQ $12 \mathrm{~km}$ modeling domain, these five analysis regions, and the location of the AQS monitors, CASTNET monitors, and ozonesonde sites used in the analysis.

\section{Results and discussion}

\subsection{Analysis of BASE CMAQ simulations}

\subsubsection{Evaluation summary}

Before analyzing ozone results for the sensitivity simulations, this section provides an overview of ozone model performance in the five analysis regions used in this study for the BASE simulation. Results for meteorology, ozone, and other pollutants from these simulations were already analyzed and compared to other models in Solazzo et al. (2017a, b).

Table 3 provides a summary of model performance for the BASE simulation for MDA8 ozone at AQS monitors over the five analysis regions shown in Fig. 2. The metrics shown in this table are the normalized mean bias (NMB), normalized mean error (NME), and correlation coefficient $(R)$. These 


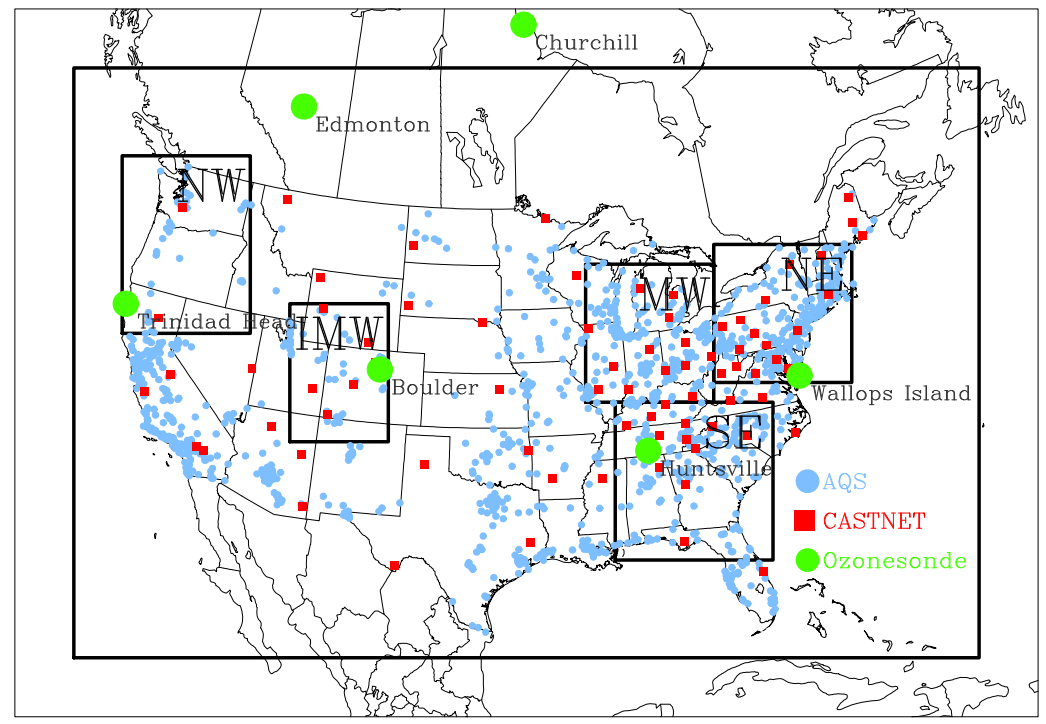

Figure 2. Map of the $12 \mathrm{~km}$ CMAQ modeling domain, the five analysis domains, and the location of the AQS and CASTNET surface $\mathrm{O}_{3}$ monitoring stations and ozonesonde launch sites.

Table 3. Seasonal model performance for MDA8 ozone at AQS sites as measured by normalized mean bias (NMB), normalized mean error (NME), and correlation coefficient for the BASE simulations for all sites and the five analysis regions is shown in Fig. 2. The metrics were computed at each AQS site for each season, and the median metric across all sites in a given region and season is shown in this table. The fonts used in the table are based on the model evaluation goals and acceptability criteria proposed by Emery et al. (2017). Cells in normal font indicate regions and seasons where model performance meets the goal for a given metric (NMB $< \pm 5 \%, \mathrm{NME}<15 \%$, and $R>0.75$ ), cells in italics indicate regions and seasons where model performance meets the acceptability criterion but not the goal $( \pm 5 \%<\mathrm{NMB}< \pm 15 \%$, $15 \%<\mathrm{NME}<25 \%$, and $0.5<R<0.75$ ), and cells in bold font indicate regions and seasons where neither the goal nor the acceptability criterion are met $(\mathrm{NMB} \geq \pm 15 \%, \mathrm{NME} \geq 25 \%$, and $R \leq 0.5)$.

\begin{tabular}{llrrrrrr}
\hline & & All & NW & IMW & MW & SE & NE \\
\hline \multirow{2}{*}{ NMB } & Spring & 2.1 & 9.1 & 3.6 & 2.0 & 2.6 & -3.2 \\
& Summer & 6.8 & 13.5 & -3.2 & 6.3 & 9.6 & 2.6 \\
& Fall & 3.1 & 13.0 & 2.1 & 1.0 & 2.1 & 1.7 \\
& Winter & -5.1 & 11.0 & -2.8 & $-\mathbf{2 3 . 1}$ & -7.3 & $\mathbf{- 2 8 . 2}$ \\
\hline \multirow{2}{*}{ NME } & Spring & 11.3 & 13.1 & 8.5 & 11.3 & 11.3 & 12.0 \\
& Summer & 13.6 & 16.2 & 10.5 & 13.3 & 14.7 & 12.0 \\
& Fall & 13.5 & 20.8 & 9.4 & 12.1 & 11.7 & 14.4 \\
& Winter & 18.8 & 20.5 & 19.2 & $\mathbf{2 8 . 8}$ & 12.0 & $\mathbf{2 9 . 1}$ \\
\hline \multirow{2}{*}{$R$} & Spring & 0.75 & 0.57 & 0.66 & 0.8 & 0.82 & 0.74 \\
& Summer & 0.73 & 0.78 & 0.67 & 0.7 & 0.72 & 0.82 \\
& Fall & 0.82 & 0.72 & 0.74 & 0.84 & 0.81 & 0.87 \\
& Winter & 0.65 & 0.57 & 0.6 & 0.75 & 0.76 & 0.69 \\
\hline
\end{tabular}

metrics were computed at each site for each season, and the median metric across all sites in a given region and season is shown in Table 3. The fonts used in the table are based on the model evaluation goals and acceptability criteria proposed by Emery et al. (2017) based on a review of published model evaluation studies. Cells in normal font indicate regions and seasons where model performance meets the goal for a given metric $(\mathrm{NMB}< \pm 5 \%, \mathrm{NME}<15 \%$, and $R>0.75$ ), cells in italics indicate regions and seasons where model performance meets the acceptability criterion but not the goal $( \pm 5 \%<\mathrm{NMB}< \pm 15 \%, 15 \%<\mathrm{NME}<25 \%$, and $0.5<R<0.75$ ), and cells in bold font indicate regions and seasons where neither the goal nor the acceptability criterion are met $(\mathrm{NMB} \geq \pm 15 \%, \mathrm{NME} \geq 25 \%$, and $R \leq 0.5)$. Regionally, results show that model performance tends to be worst in NW compared to other regions, while seasonally, model performance tends to be worst during winter compared to other seasons. The three instances of model perfor- 
(a) Unpaired in time

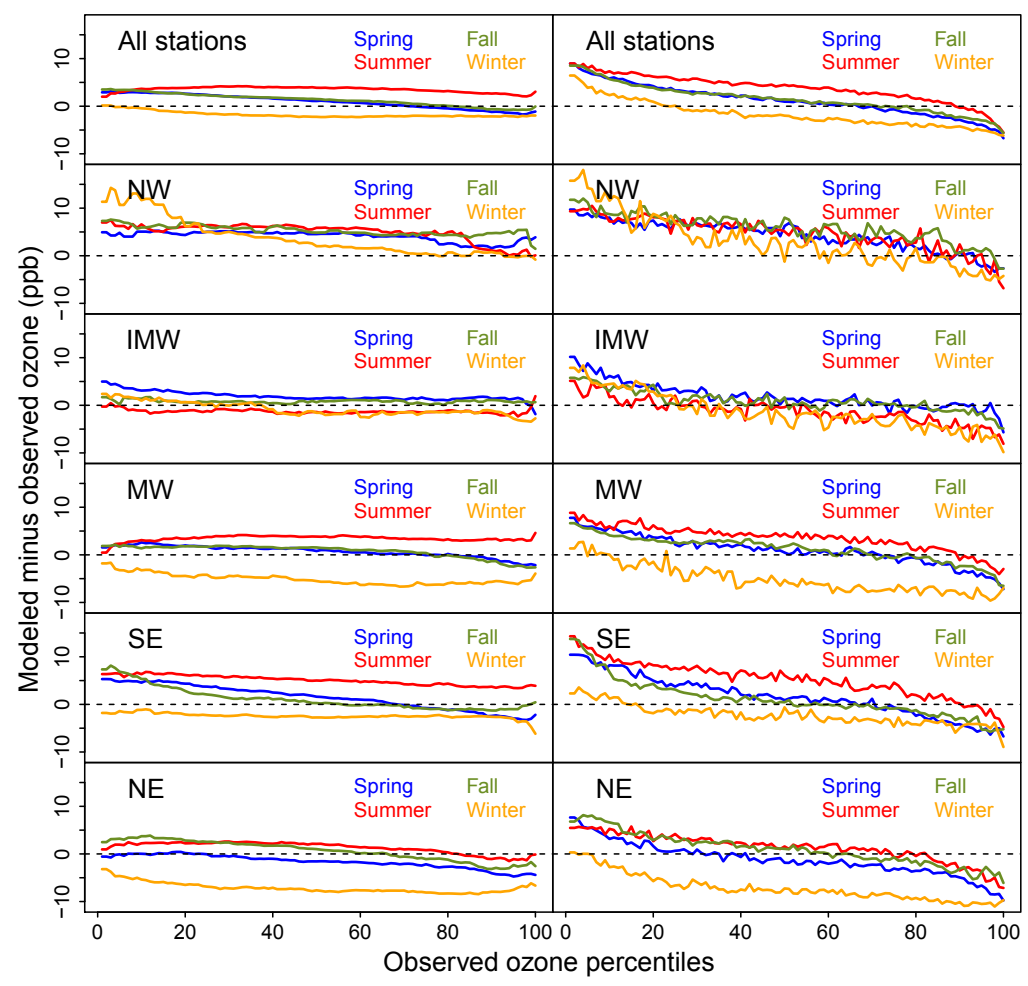

Figure 3. Differences between observed and BASE-modeled MDA8 ozone at AQS stations for each season and analysis region. For each season and region, the observed MDA8 ozone concentrations were rank ordered at each station. Next, differences between CMAQ simulations and observations were computed for each observed percentile either by selecting the model value corresponding to the date of the observed percentile (paired-in-time comparison, b) or rank ordering the model values and then selecting the modeled percentile corresponding to the observed percentile (unpaired-in-time comparison, a). Finally, the median value of these paired-in-time and unpaired-in-time differences across all AQS stations in a given season and region was then computed for each observed percentile and is depicted in this figure.

mance not meeting the acceptability criterion proposed by Emery et al. (2017) all occur during the winter. Except for NW, NMB is negative during winter in all regions, suggesting that large-scale ozone background concentrations specified through C-IFS-provided model boundary conditions may be underestimated in this simulation, particularly over the northern portion of the modeling domain. This is consistent with the findings of Flemming et al. (2017).

The model performance overview presented in Table 3 does not provide information on the ability of the BASE simulation to capture different portions of the observed MDA8 ozone distribution. To this end, we also computed differences between observed and modeled MDA8 ozone distributions at AQS monitors for each season and analysis region. For each season and region, the observed MDA8 ozone concentrations were rank ordered at each station. Differences between CMAQ simulations and observations were then computed for each observed percentile either by selecting the model value corresponding to the date of the observed percentile (pairedin-time comparison) or rank ordering the model values and then selecting the modeled percentile corresponding to the observed percentile (unpaired-in-time comparison). The median value of these paired-in-time and unpaired-in-time differences across all AQS stations in a given season and region was then computed for each observed percentile and is shown in Fig. 3.

One general feature visible throughout all seasons and regions is that the unpaired-in-time differences tend to be more flat across the range of the observed percentiles while the curves for the paired-in-time differences tend to have a negative slope. This different behavior of the unpaired-in-time and paired-in-time comparison indicates that the CMAQ simulations have better skill in capturing the width of the observed MDA8 distribution than in capturing the timing of specific observed ozone events. NW is the only region with positive unpaired-in-time differences throughout all seasons. IMW has the least spread in model performance across seasons for all percentiles, both in terms of unpaired-in-time and paired-in-time differences. Unpaired-in-time winter results for the MW, SE, and NE show an underestimation of observed MDA8 ozone across all percentiles. This is also true for the comparison of paired-in-time differences for all 
observed percentiles greater than the 20th percentile. In contrast, summer differences in these regions tend to be positive for all but the highest percentiles. For all regions, modelobservation differences for spring and fall tend to be similar to each other. For the MW, SE, and NE regions, differences for these seasons fall between the winter and summer results with consistently small unpaired-in-time differences and a tendency to overestimate lower observed percentiles and underestimate higher observed percentiles when considering paired-in-time differences. The analysis presented in Sect. 3.2.3 will explore the sensitivity of these model performance results towards alternate lateral boundary conditions.

\subsubsection{Process analysis contributions to ozone columns}

The analysis above focused on ground-level ozone evaluation. Ground-level ozone is affected by a number of physical and chemical processes both near the surface and aloft. The PA tool in CMAQ (Jeffries and Tonnesen, 1994; Jang et al., 1995) provides a method to track these process contributions to the modeled ozone. In this study, we configured PA to track the contributions of the following processes to simulated ozone: horizontal advection (HADV), vertical advection (ZADV), horizontal diffusion (HDIF), vertical diffusion (VDIF), dry deposition (DDEP), chemistry (CHEM), and cloud processes including vertical mixing by convective clouds and removal through scavenging and aqueous chemistry (CLDS). The resulting process contributions are available for each grid cell and each hour throughout the annual simulation.

Figure 4 shows profiles of seasonal total ozone column mass changes for each model layer due to the seven processes summed over the entire modeling domain. The PA terms represent the net change in ozone mass due to a given process in a given model layer and season. For almost all layers and seasons, HADV and ZADV are of similar magnitude and opposite direction due to mass-consistent advection and are the dominant processes for layers above $\sim 800 \mathrm{mb}$. In the first model layer, DDEP is a strong sink of ozone, balanced largely by VDIF, i.e., flux of ozone from upper layers to the surface. VDIF tends to become insignificant above $\sim 500 \mathrm{mb}$ while the effect of HDIF is negligible for all model layers. CHEM is a sink in the first model layer, a source in the boundary layer, and a net sink between approximately 800 and $400 \mathrm{mb}$ for all seasons except winter. CLDS tends to be a source of ozone in the lower atmosphere and a sink in the upper atmosphere.

To better illustrate the seasonal variations of the process contributions in the upper model layers, free troposphere, and boundary layer/lower troposphere, Fig. 5 presents monthly domain-wide total PA contributions to ozone columns in CMAQ layers 1-21 (surface to approximately $750 \mathrm{mb}$ ), 2231 (approximately $750-250 \mathrm{mb}$ ), and 32-35 (approximately $250-50 \mathrm{mb}$ ). The horizontal and vertical advection and dif-

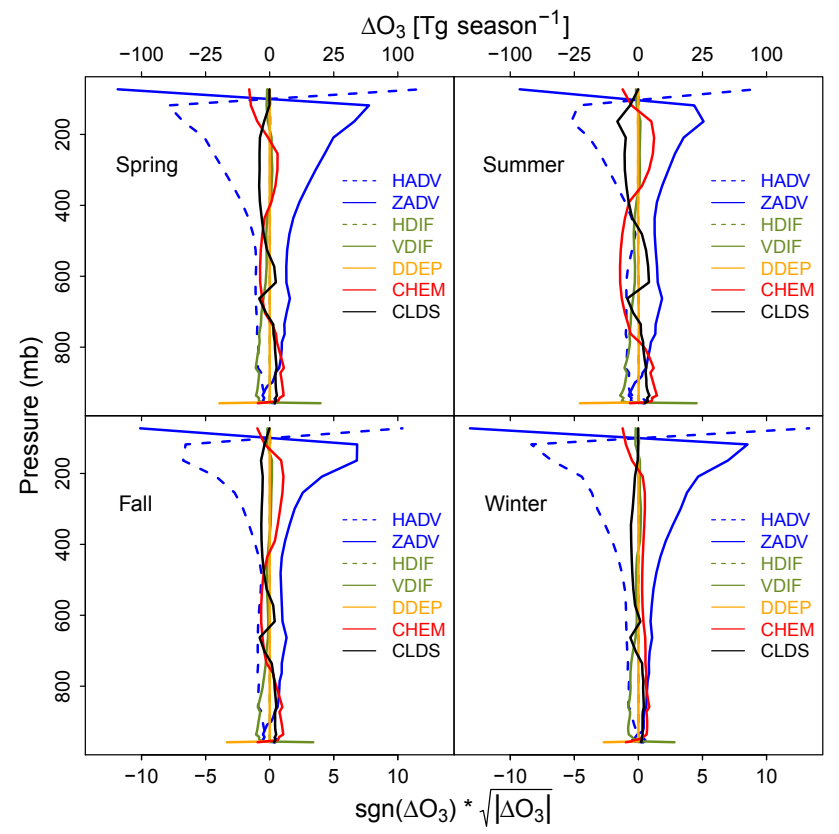

Figure 4. Profiles of BASE seasonal total ozone column mass changes $\Delta \mathrm{O}_{3}$ for each CMAQ model layer due to the effects of horizontal advection (HADV), vertical advection (ZADV), horizontal diffusion (HDIF), vertical diffusion (VDIF), dry deposition (DDEP), chemistry (CHEM), and cloud processes including vertical mixing by convective clouds (CLDS). The values are summed over the entire modeling domain and represent the net change in ozone mass due to a given process in a given model layer and season.

fusion terms were summed to compute the effects of total advection (TADV) and total diffusion (TDIF), respectively. Consistent with the profiles shown in Fig. 4, changes in ozone mass in the upper layers are dominated by TADV, with these layers gaining ozone mass through TADV early and late in the year when tropopause heights are lower, and a larger portion of the lower stratosphere is included in the model while they tend to lose mass through the effects of TADV from April to September. The column between 250 and $750 \mathrm{mb}$ gains ozone mass through TADV for almost all months, indicating that both lateral boundary conditions and ozone in the upper layers determine the ozone column burden simulated in the free troposphere. CHEM is a net sink especially during summer. Vertical mixing by convective clouds also removes ozone from these layers while the effect of TDIF is small. The ozone column below $750 \mathrm{mb}$ gains mass through the effects of CHEM especially during summer as well as through the effects of vertical mixing by convective clouds that tap into the ozone reservoir in the free troposphere to enhance the lower atmospheric ozone burden. The dominant sink term of ozone mass in this layer range is DDEP at the surface. TADV and TDIF play a secondary role in modifying the total ozone burden in this column range. It should be noted that the PA results shown in 


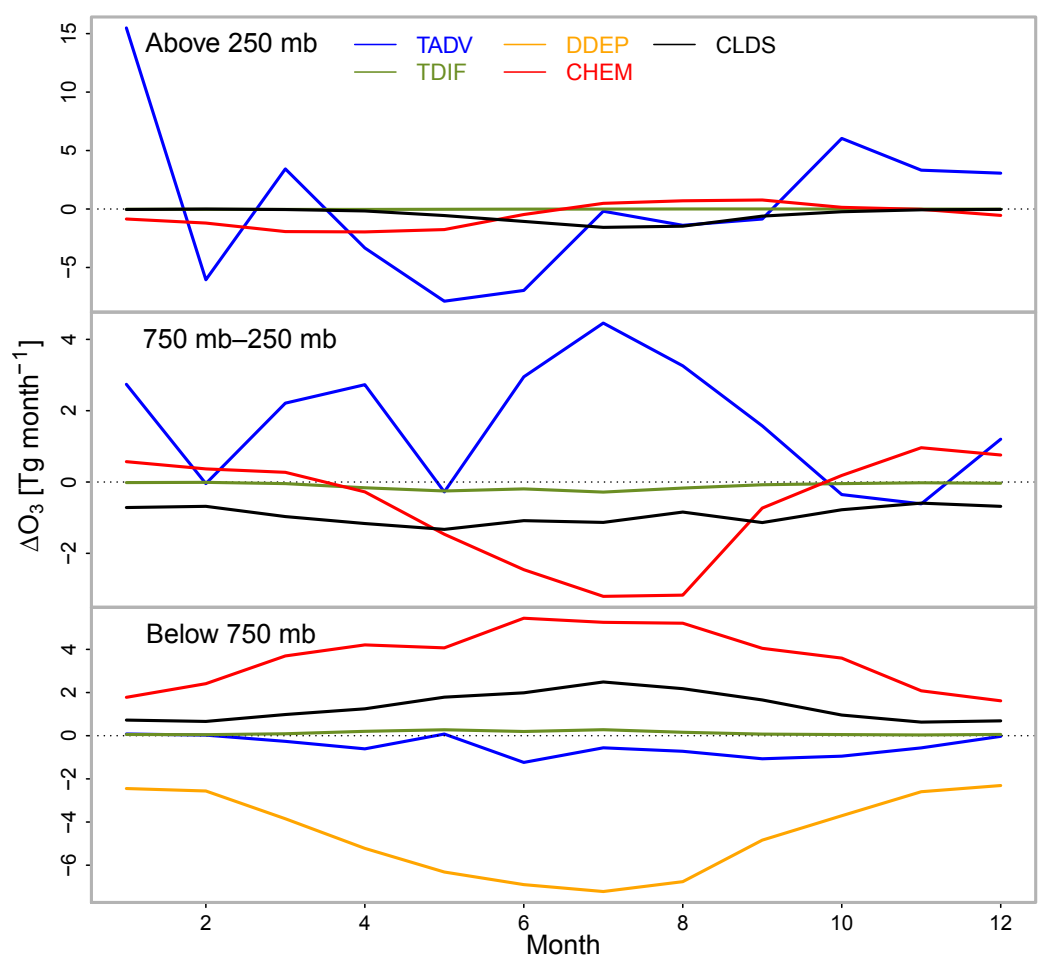

Figure 5. Time series of monthly domain-wide total process analysis contributions to BASE ozone columns in CMAQ layers 1-21 (surface to approximately $750 \mathrm{mb}$ ), 22-31 (approximately 750-250 mb), and 32-35 (approximately 250-50 mb). The horizontal and vertical advection and diffusion terms were summed to compute the effects of total advection (TADV) and total diffusion (TDIF), respectively.

Figs. 4-5 are based on a single year. Interannual variability would be expected to affect the absolute magnitude and month-to-month variations especially of the advection processes; however, the qualitative differences in process rankings between different layer ranges would be expected to be robust with respect to interannual variability. Moreover, the process contributions presented here are monthly totals over the entire domain. Contributions for specific locations and episodes would likely differ. For example, while the CLDS term is shown to be a net source for lower-tropospheric ozone over the entire domain, it might be a net sink during episodes of high ozone formation in the boundary layer. Overall, the results indicate that alternate model representation of advection, dry deposition, and cloud processes, as well as alternate model inputs (boundary conditions affecting advected ozone and emissions affecting ozone chemistry) would be expected to have noticeable effects on the simulated ozone burdens and their seasonal variation. Hypothetical bounding scenarios quantifying the effects of emissions, boundary conditions, and ozone dry deposition on the simulated ozone burden are explored in the next section.

\subsubsection{Brute-force bounding simulations}

The upper three panels of Fig. 6 present time series of the monthly average ozone column mass for the BASE, BC
ZERO, EM ZERO, and NO O3 DDEP sensitivity simulations for the same three layer ranges analyzed in the previous section while the lowest panel presents time series of monthly average ozone mixing ratios for the first model layer. These time series confirm the PA findings that the ozone column burden above $250 \mathrm{mb}$ is almost entirely driven by advection of lateral boundary conditions in these continental-scale CMAQ simulations. Specifically, in this layer range, the BC ZERO simulation has an ozone column of essentially zero while the burdens simulated for the EM ZERO and NO O3 DDEP cases are indistinguishable from the burden simulated for the BASE case. The results for the free troposphere (750$250 \mathrm{mb}$ ) show a small difference in the column base simulated by the BASE and EM ZERO simulations especially during summer. This difference quantifies the net effects of ozone production from emissions but is dwarfed by the impacts from the BC ZERO simulation which again is suggestive that the variability in the free troposphere is largely driven by the specification of lateral boundary conditions. Results for the column from the surface to $750 \mathrm{mb}$ show noticeable differences in ozone column mass between all four simulations, with the differences with respect to the BASE simulation being lowest for the NO O3 DDEP case and highest for the BC ZERO case. For the surface ozone monthly mean mixing ratio, the largest signal is seen for the $\mathrm{NO} O 3$ DDEP case followed by the BC ZERO case. The EM ZERO 


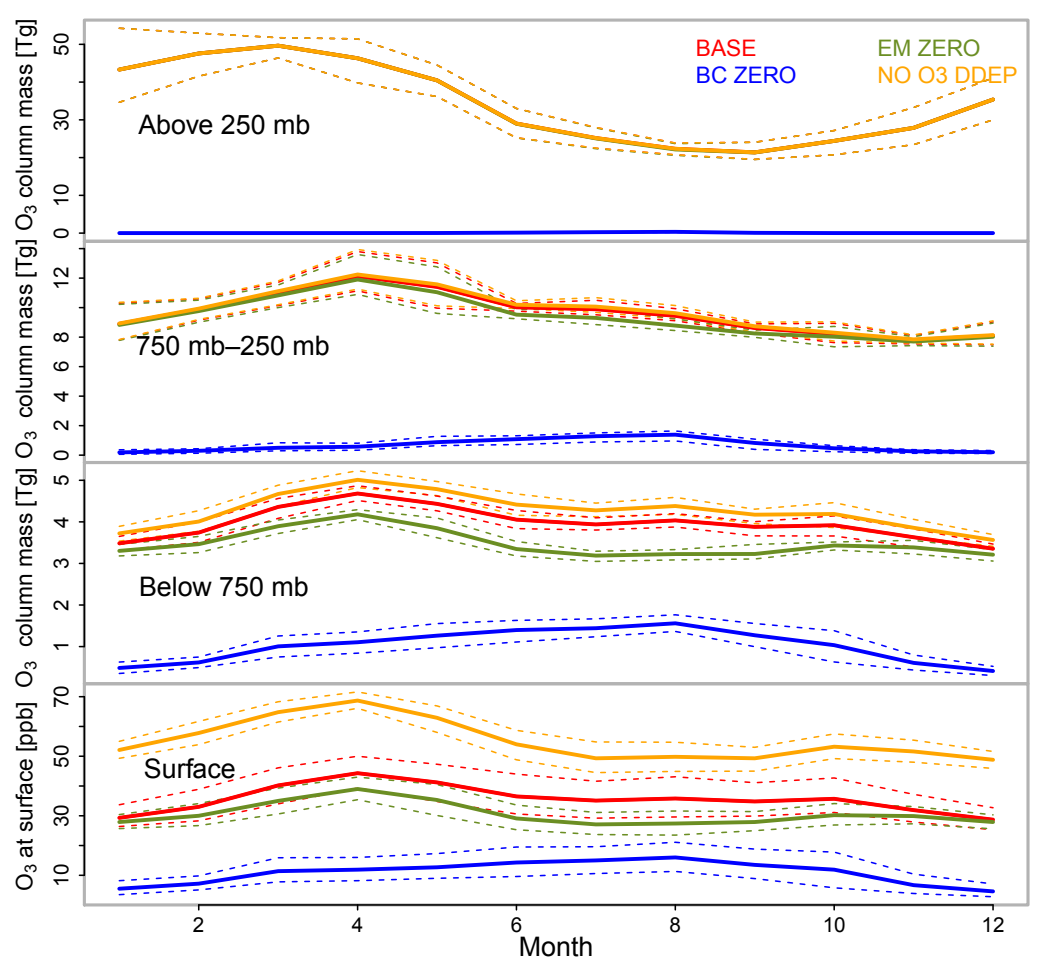

Figure 6. The upper three panels present time series of the monthly average domain-total ozone column mass for the BASE, BC ZERO, EM ZERO, and NO O3 DDEP sensitivity simulations for the same three layer ranges analyzed in Fig. 5 while the lowest panel presents time series of monthly average domain-average ozone mixing ratios for the first model layer. The dashed lines represent the 5th and 95th percentiles of the hourly domain-total ozone column mass and domain-average ozone mixing ratios for a given month.

case has the smallest impact at the surface but, as shown above, emissions have a larger cumulative impact on column ozone burden than dry deposition.

Furthermore, the surface results for the BASE, BC ZERO, and EM ZERO sensitivity simulations indicate that during wintertime, domain-average simulated ozone mixing ratios are almost exclusively driven by boundary conditions; i.e., BASE and EM ZERO are very similar despite the lack of anthropogenic emissions in the latter, and mixing ratios in the BC ZERO simulation are close to $0 \mathrm{ppb}$. The EM ZERO results also indicate that the impact of boundary conditions on regional ozone is largest in springtime when freetropospheric ozone in the Northern Hemisphere reaches a maximum. If one views the ozone from the EM ZERO simulation as the amount of regional ozone due to boundary conditions and biogenic emissions, and BC ZERO as the amount of ozone due to anthropogenic and biogenic emissions within the domain, the results indicate that the former dominates the latter throughout the year in terms of domainaverage monthly mean mixing ratios at the surface. However, it should be noted that the impacts of these bounding simulations on simulated surface ozone vary spatially. Solazzo et al. (2017b) analyzed seasonal cycles from these simulations sampled at ozone monitoring locations and found that during the summertime the impact of anthropogenic emis- sions on monthly mean concentrations was comparable to or larger than the impact of boundary conditions in the subregions considered in their analysis.

To investigate the spatial variability of surface ozone from these bounding scenarios, Fig. 7 shows maps of differences in seasonal mean mixing ratios between the three sensitivity simulations (BC ZERO, EM ZERO, and NO O3 DDEP) and the BASE simulation. The results show that as expected the impact of zeroing out boundary conditions decreases with distance from the boundaries in all seasons, with the smallest impacts typically seen in the southeastern portion of the modeling domain. In contrast, the effects of zeroing out the anthropogenic and wildfire emissions tend to be largest in the eastern portion of the modeling domain, leading to larger decreases in simulated ozone compared to the BC ZERO case during summer in that region. Increases of seasonal mean ozone can be observed in urban areas for the EM ZERO simulation in all seasons. The effects of ozone dry deposition on simulated seasonal mean surface ozone mixing ratios is most pronounced in the eastern portion of the modeling domain during spring and especially summer, with increases of more than $20 \mathrm{ppb}$ simulated across a broad region. These NO O3 DDEP results indicate that intercomparing and evaluating ozone dry deposition approaches would be a fruitful avenue for future model intercomparison activities aimed at better 


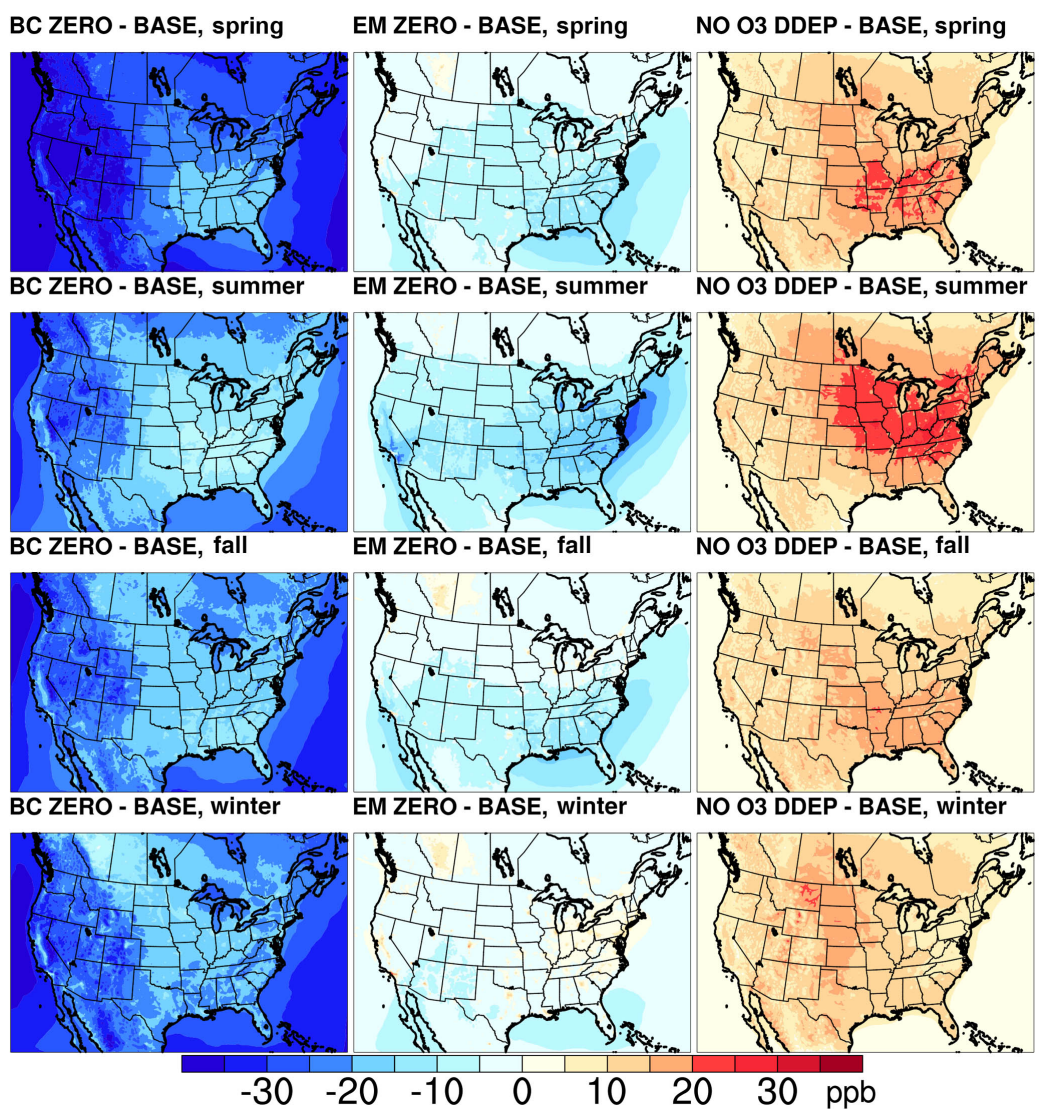

Figure 7. Maps of differences in seasonal mean ozone mixing ratios between the three sensitivity simulations (BC ZERO, EM ZERO, and NO O3 DDEP) and the BASE simulation.

constraining processes affecting surface ozone fluctuations simulated by different models.

Overall, the analysis of the brute-force sensitivity simulations presented in this section as well as the process analysis results presented in Sect. 3.1.2 confirm that the characterization of ozone outside the regional-scale modeling domain can have a profound impact on simulated regional-scale ozone. However, these brute-force bounding simulations do not represent plausible representations of real-world conditions. In the next section, we present regional-scale CMAQ simulations utilizing boundary conditions derived from different large-scale models. This is aimed at investigating the impact of different state-of-the-science representations of the global atmosphere on air quality simulated over the United States with a $12 \mathrm{~km}$ resolution regional-scale model.

\subsection{Analysis of CMAQ simulations with boundary conditions from different global models}

\subsubsection{Comparisons of aloft concentrations from global models and regional CMAQ}

Figure S1 in the Supplement shows time-height cross sections of monthly mean ozone mixing ratios along the west- ern, southern, eastern, and northern boundaries of the regional CMAQ domain for the four large-scale models from which boundary conditions were derived. The mixing ratios were averaged over all columns or rows defining a given boundary and also were averaged for each month. For all boundaries, GEOS-Chem and C-IFS tend to have the highest ozone mixing ratios for levels above $150 \mathrm{mb}$. All models show a springtime maximum and fall minimum for these levels. During springtime, AM3 shows the deepest intrusion of higher ozone mixing ratios from upper levels to mid- and lower-tropospheric levels at the western, northern, and eastern boundaries.

Time-height cross sections of monthly mean ozone were also prepared at the location of the six ozonesonde stations shown in Fig. 2. These monthly mean mixing ratios were calculated for observations, the four large-scale models, and the corresponding four regional CMAQ simulations. Since ozonesonde measurements are available at a much higher vertical resolution than the model simulations, observations were vertically averaged to the vertical structure used by each model (see Fig. 1) and the observations as averaged to the C-IFS layer structure are depicted in Fig. 8a-b. Note that even though observations and large-scale model predictions (except H-CMAQ) are available for higher altitudes 
(a)
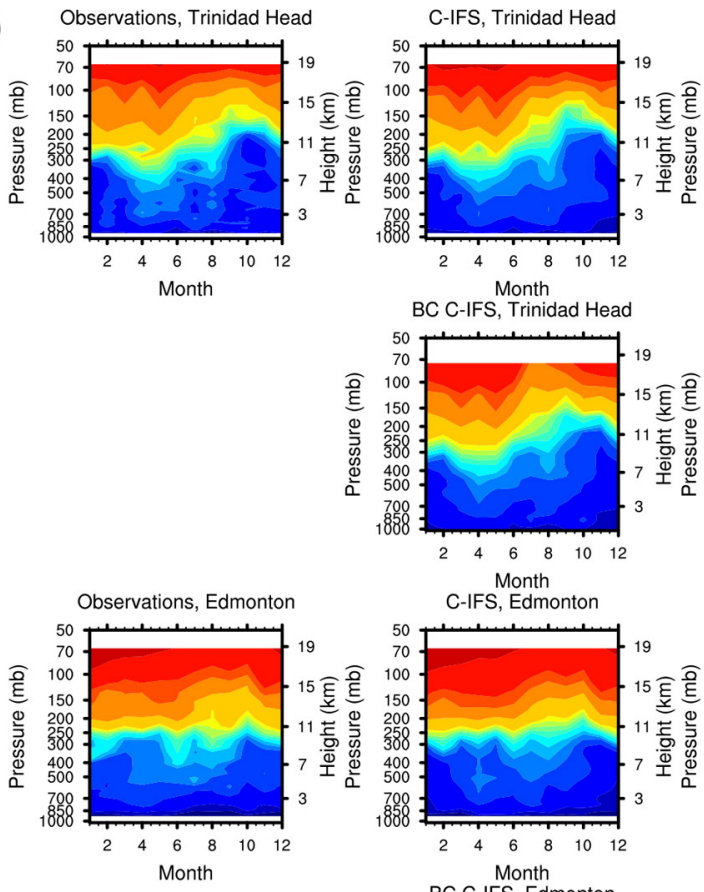

BC C-IFS, Edmonton
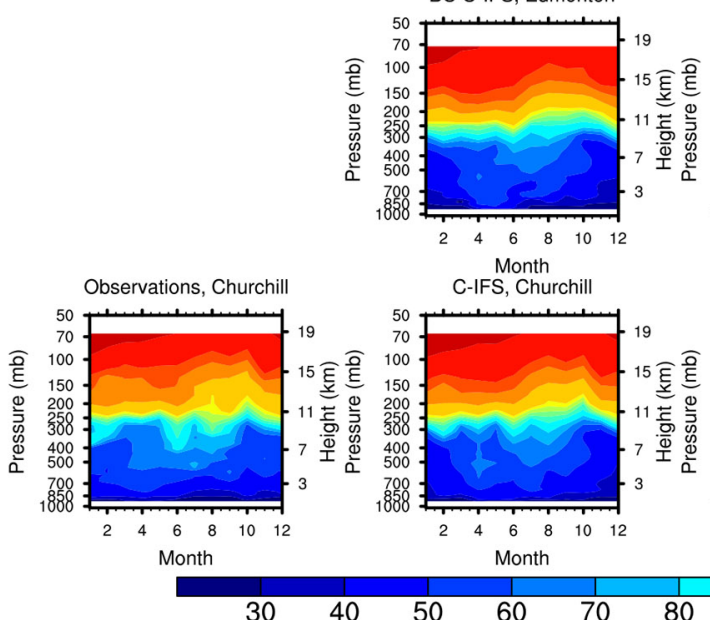
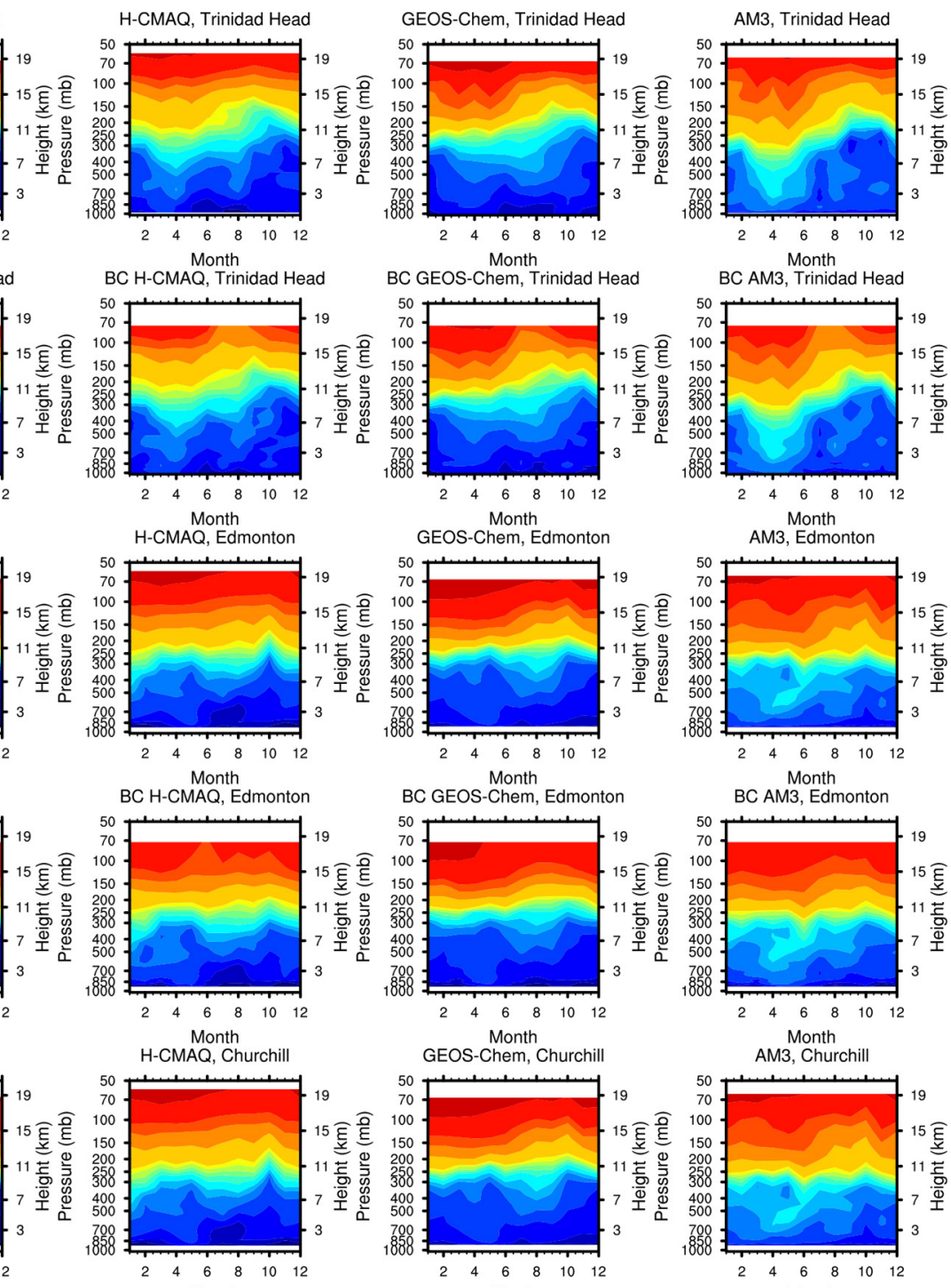

BC AM3, Edmonton

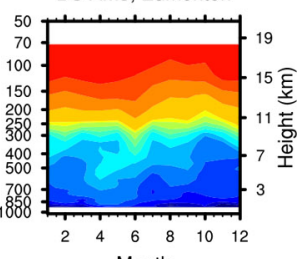

GEOS-Chem, Churchill

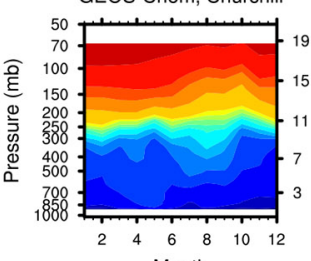

Month

AM3, Churchil

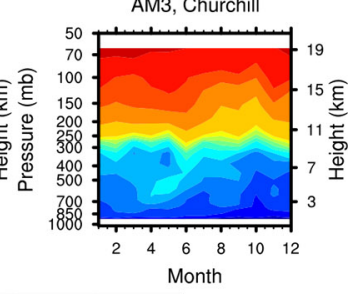

$10002000 \mathrm{ppb}$

Figure 8.

(see Fig. 1), only values up to the highest model level below $50 \mathrm{mb}$ were extracted for these figures to be comparable to the output from the regional-scale CMAQ simulations (specifically, C-IFS values were only extracted up to layer 38, GEOS-Chem values were only extracted up to layer 37 , and AM3 values were only extracted up to layer 26 for this comparison). For easier comparison between models and sites, all figures use a common vertical pressure range of 1025 to $50 \mathrm{mb}$ even though this full range is not covered at all sites and by all models. Figure 8a shows the time-height cross sections for the three ozonesonde sites that are located in close proximity of the western and northern regional CMAQ boundaries (i.e., Trinidad Head, Edmonton, and Churchill) where inflow into CMAQ is expected to be most important due to prevailing flow patterns. The cross sections for the large-scale models in rows 1,3 , and 5 are consistent with the cross sections for the western and northern boundaries shown in Fig. S1. In particular, GEOS-Chem and C-IFS tend to have the highest ozone mixing ratios for levels above $150 \mathrm{mb}$ while AM3 shows the deepest intrusion of higher ozone mixing ratios from upper levels to mid- and lowertropospheric levels especially during springtime. Comparing the large-scale model results to the observed cross sections in the left column reveals that free-tropospheric mixing ratios simulated by C-IFS, H-CMAQ, and GEOS-Chem tend to be closer to the observations than the mixing ratios simulated by AM3 which tend to be overestimated. Another key feature of the cross sections shown in Fig. 8a is that 

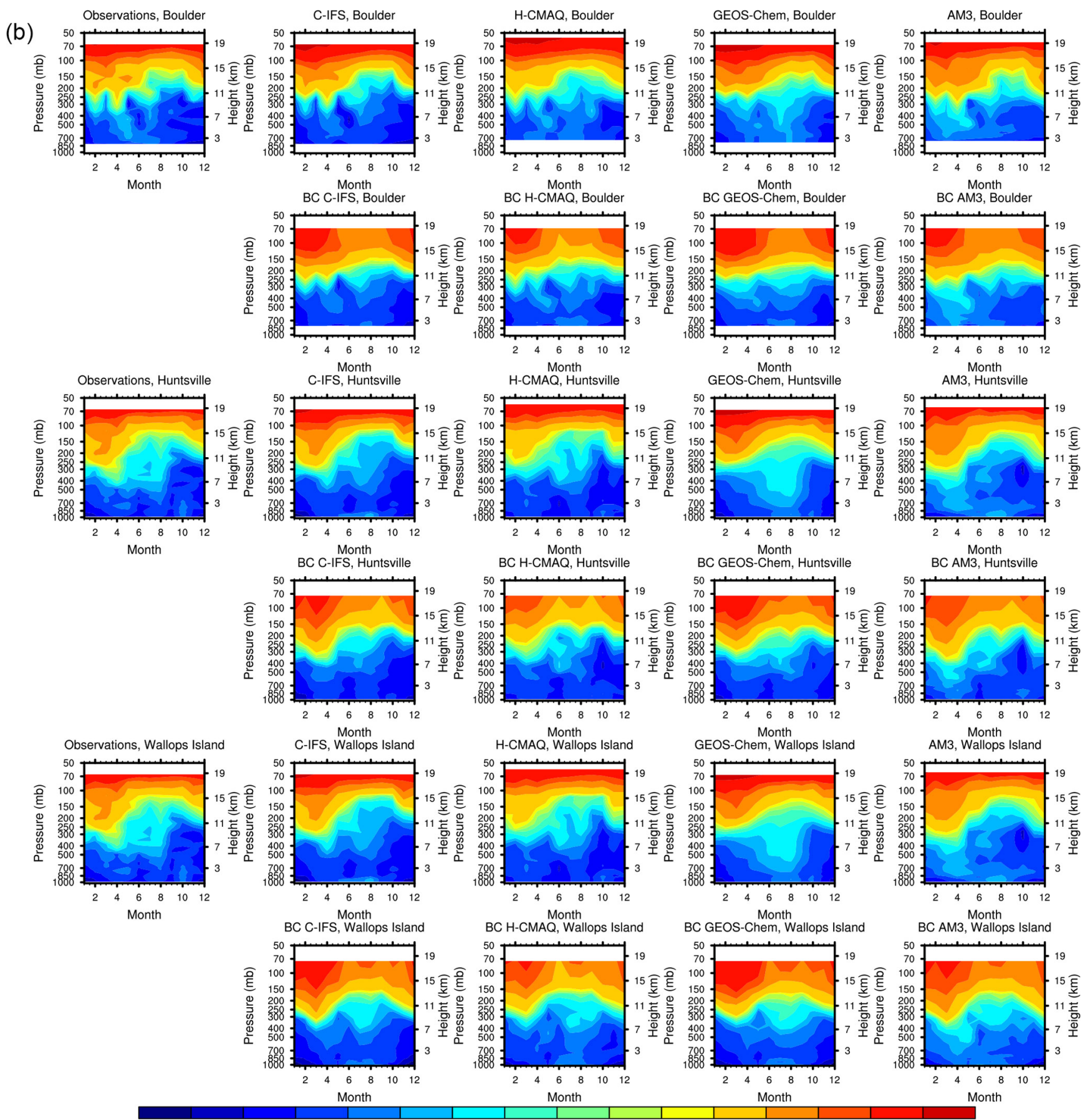

$$
30 \quad 40 \quad 50
$$

Figure 8. (a) Time-height cross sections of monthly mean ozone mixing ratios for ozonesonde observations (column 1), large-scale models (columns 2-5 in rows 1, 3, and 5), and regional CMAQ simulations (columns 2-5 in rows 2 and 4) at Trinidad Head, Edmonton, and Churchill. Note that no regional CMAQ results are shown for Churchill because the station is located outside the regional model domain. Additional details on the processing of observations and model simulations are provided in the text. (b) Time-height cross sections of monthly mean ozone mixing ratios for ozonesonde observations (column 1), large-scale models (columns 2-5 in rows 1, 3, and 5), and regional CMAQ simulations (columns 2-5 in rows 2, 4, and 6) at Boulder, Huntsville, and Wallops Island. Additional details on the processing of observations and model simulations are provided in the text. 


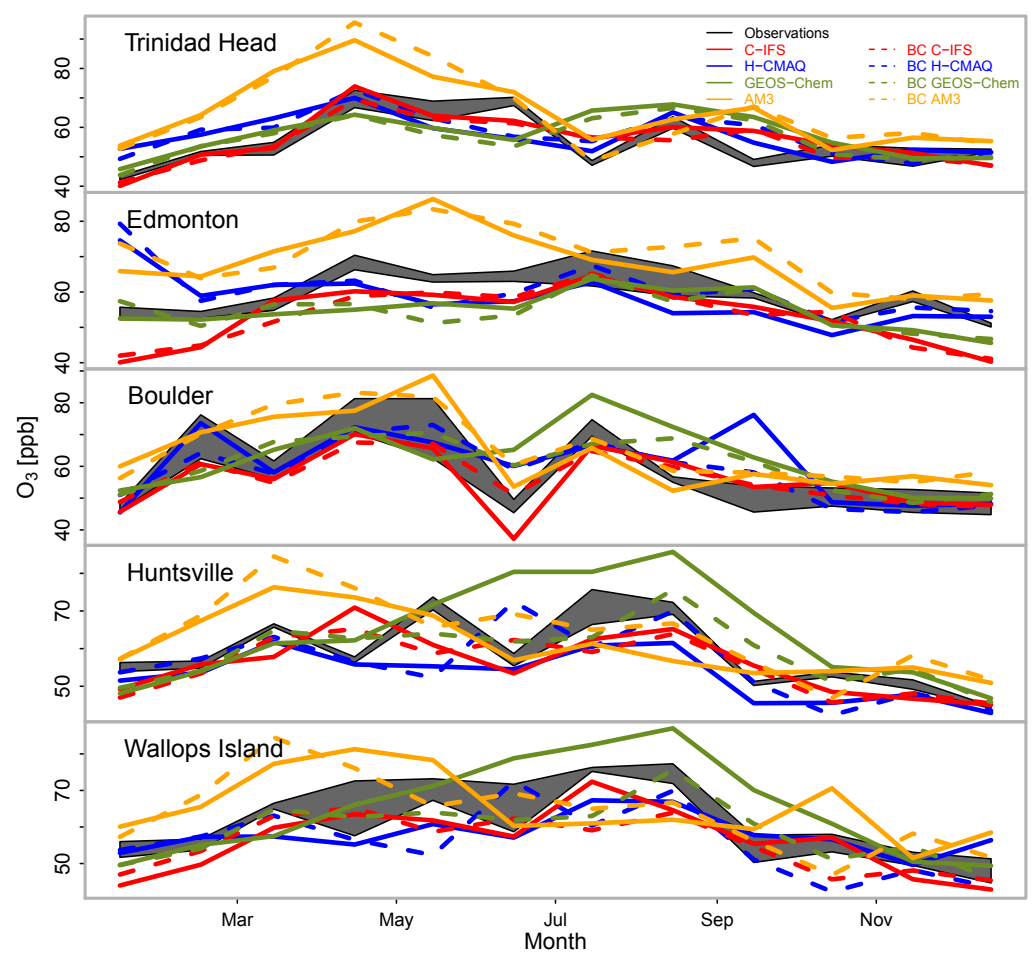

Figure 9. Monthly average time series of $500 \mathrm{mb}$ observed ozone, ozone simulated by large-scale models (solid lines), and ozone simulated by regional CMAQ driven with boundary conditions from different large-scale models (dashed lines) at Trinidad Head, Edmonton, Boulder, Huntsville, and Wallops Island. Additional details on the processing of observations and model simulations are provided in the text.

the regional CMAQ results at Trinidad Head and Edmonton shown in rows 2 and 4 closely mirror those simulated by the corresponding large-scale models, emphasizing the impact of boundary conditions on regional-scale simulations especially near the boundaries (note that no regional-scale results are shown for Churchill as the station is located outside the $12 \mathrm{~km}$ modeling domain shown in Fig. 2).

Figure $8 \mathrm{~b}$ shows corresponding results for the three ozonesonde locations in the interior of the regional-scale CMAQ modeling domain: Boulder, Huntsville, and Wallops Island. At all of these sites, AM3 tends to simulate higher free-tropospheric and lower-tropospheric mixing ratios than the other large-scale models during spring while GEOS-CHEM tends to simulate higher mixing ratios during summer. The observed cross section at Boulder suggests that no large-scale model performs systematically better or worse than another at this location in the free troposphere. At Huntsville and Wallops Island, free-tropospheric mixing ratios are overestimated by AM3 during spring and by GEOSCHEM during summer. Finally, the comparison between the regional CMAQ cross sections and the corresponding largescale model cross sections at these three sites shows some differences as well as similarities, indicating that differences in factors such as the treatment of vertical mixing, lightning emissions, chemistry, deposition, and biogenic emissions can lead to deviations between the large-scale models and the regional CMAQ simulations over the continental United States.

The connection between large-scale models and the corresponding regional CMAQ simulations is further explored in Fig. 9. This figure shows monthly average time series of $500 \mathrm{mb}$ observed ozone, ozone simulated by the largescale models (solid lines), and ozone simulated by regional CMAQ driven with boundary conditions from the different large-scale models (dashed lines) at Trinidad Head, Edmonton, Boulder, Huntsville, and Wallops Island. Model simulations were extracted for the layer closest to $500 \mathrm{mb}$ and observations were vertically averaged across the depth of each of these different model layers. As a result of the different vertical structure of the four large-scale models and the regional CMAQ simulations depicted in Fig. 1, five different estimates of $500 \mathrm{mb}$ observations were derived and the range of these different estimates is indicated by the shaded area in Fig. 9. Between March and June, AM3 mixing ratios are up to $20 \mathrm{ppb}$ higher than the mixing ratios simulated by the other three large-scale models at Trinidad Head, Boulder, and Wallops Island, and up to $10 \mathrm{ppb}$ higher at Boulder and Huntsville. At all sites except Boulder, the AM3 simulations are also systematically higher than observations during this time period. At the sites closest to the western and northern inflow boundaries, i.e., Trinidad Head and Edmonton, the time series for the regional CMAQ results closely mir- 
ror those for the corresponding large-scale models. Within the modeling domain, there is more separation of the largescale and regional CMAQ results, especially between the GEOS-Chem and BC GEOS-Chem results during summer at Huntsville and Wallops Island where BC GEOS-Chem simulates substantially lower mixing ratios than GEOS-Chem. These differences may be at least partially due to the representation of emissions from lightning. While the regional CMAQ simulations did not include lightning NO emissions, they were included in the GEOS-Chem simulations. Zhang et al. (2014) and Travis et al. (2016) note that the standard GEOS-Chem treatment of lightning $\mathrm{NO}_{x}$ yields for midlatitudes may be too high and can lead to positive ozone biases at the surface.

The differences in the magnitude of mid-tropospheric ozone mixing ratios between the large-scale models at the more remote Trinidad Head, Edmonton, and Churchill sites point to differences in the representation of stratospheric ozone and stratosphere-troposphere exchange processes. The representation of the latter might also be affected by differences in vertical resolution as shown in Fig. 1. In conjunction with the results presented in Sect. 3.1, Figs. 8 and 9 also suggest that regional-scale CMAQ simulations using these four different sets of boundary conditions will yield different estimated ozone burdens. It should be noted that an in-depth evaluation and intercomparison of the different large-scale simulations is beyond the scope of the current study. Previous studies evaluating H-CMAQ, GEOS-Chem, C-IFS, and AM3 include Xing et al. (2015a, b), Mathur et al. (2017), Fiore et al. (2009), Flemming et al. (2015), and Lin et al. (2012a, b, 2017). Three of these simulations (GEOS-Chem, C-IFS, and AM3) are also being compared against aloft and surface ozone measurements by Cooper et al. (2018).

\subsubsection{Seasonal differences in CMAQ-simulated ozone columns}

Figure S2 shows daily time series of CMAQ-simulated domain-total ozone column mass for the same three layer ranges used in the previous sections. The results are for the BASE, BC H-CMAQ, BC GEOS-Chem, and BC-AM3 simulations. For layers $32-35$ (i.e., the layers approximately above $250 \mathrm{mb}$ ), all simulations show a maximum in spring and a minimum in fall. All simulations track each other but the magnitudes differ by up to a factor of 2 . The largest ozone abundance in the upper layers is simulated by $\mathrm{BC}$ GEOS-Chem, followed by BASE, BC AM3, and BC HCMAQ, consistent with the analysis of boundary conditions in Sect. 3.2.1. The most notable feature for the ozone column mass in layers $22-31$ (i.e., approximately $750-250 \mathrm{mb}$ ) is the larger springtime ozone burden simulated by BC AM3 compared to the other three simulations, consistent with the analysis of the ozone boundary conditions at $500 \mathrm{mb}$ in the previous section. The same feature is also found for the ozone column mass in layers 1-21 (i.e., surface to ap- proximately $750 \mathrm{mb}$ ) which confirms the notion that vertical exchange between this layer range and the free troposphere leads to a tight coupling of their ozone fluctuations. For all layer ranges, these results confirm that differences in ozone boundary conditions result in differences of CMAQsimulated ozone column mass over the modeling domain.

\subsubsection{Seasonal differences in CMAQ surface ozone mixing ratios}

Figure 10 shows maps of seasonal mean ozone mixing ratios at the surface for the four simulations. The left column shows the mixing ratios for the BASE simulation while the second, third, and fourth columns show the differences between $B C$ H-CMAQ and BASE, BC GEOS-Chem and BASE, and BC AM3 and BASE, respectively. For the BASE simulations, many regions including IMW and the central US show a springtime peak in seasonal mean ozone while summer peaks are present downwind of more urban areas such as in California and the mid-Atlantic corridor. Differences between the BASE simulations and the three sensitivity simulations are generally highest near the domain boundaries in all seasons but differences of $10 \mathrm{ppb}$ in seasonal mean $\mathrm{O}_{3}$ can be found even in the center of the modeling domain in some cases. The largest differences exist between the BC AM3 and BASE simulations and are especially pronounced during spring and winter. In contrast, the differences between BC H-CMAQ and BASE and BC GEOS-Chem and BASE are typically smaller $( \pm 4 \mathrm{ppb}$ for most of the modeling domain except for BC H-CMAQ during winter). These impacts of lateral boundary conditions on surface ozone mixing ratios are consistent with the analysis of the large-scale models and CMAQ ozone column burdens in the previous sections. Separate analysis shows that considering MDA8 ozone instead of hourly ozone leads to very similar spatial patterns of seasonal mean differences between the model simulations. This is expected since the effect of boundary conditions on the average diurnal cycle manifests itself mostly as a constant shift throughout the course of the day as shown in Solazzo et al. (2017b).

Figure 11a-f show time series of differences between modeled and observed ozone mixing ratios. Figure 11a shows results for monthly means of daytime average mixing ratios at CASTNET monitors for the four regional model simulations, Fig. 11b shows the results for the four corresponding large-scale models, Fig. 11c shows results for monthly means of daytime average mixing ratios at AQS monitors instead of CASTNET monitors for the four regional model simulations, Fig. 11d shows results for the four regional models at $\mathrm{AQS}$ monitors using monthly means of MDA8 instead of monthly means of daytime average mixing ratios, and Fig. 11e and $\mathrm{f}$ correspond to Fig. 11c and $\mathrm{d}$ but show daily rather than monthly mean values. These time series illustrate that regardless of metric (daytime average vs. MDA8) and network (CASTNET vs. AQS), all 


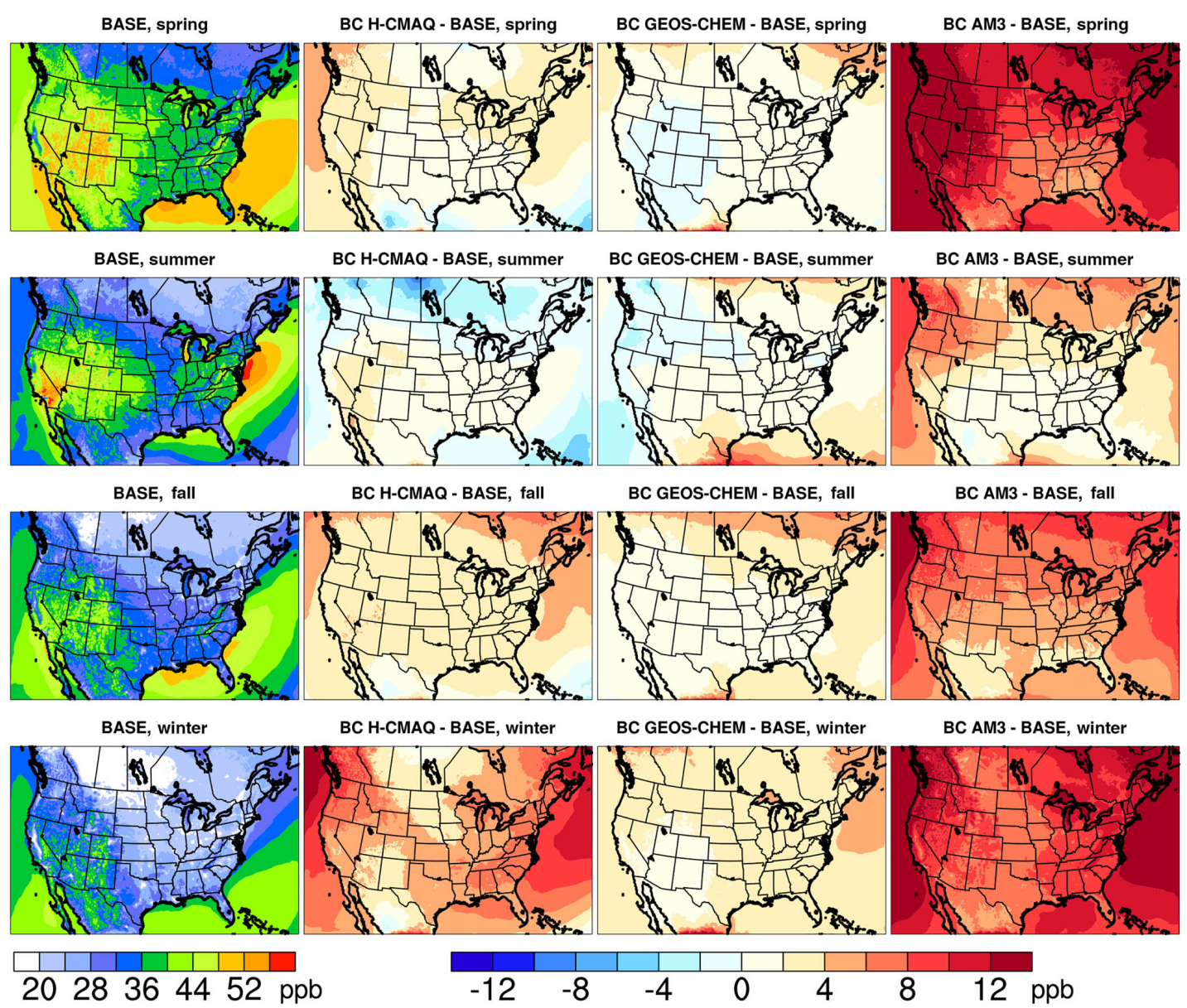

Figure 10. Maps of seasonal mean ozone mixing ratios at the surface for the BASE, BC H-CMAQ, BC GEOS-Chem, and BC-AM3 simulations. The left column shows the mixing ratios for the BASE simulation while the second, third, and fourth columns show the differences between BC H-CMAQ and BASE, BC GEOS-Chem and BASE, and BC AM3 and BASE, respectively.

regional CMAQ simulations overestimate domain-mean observed ozone throughout the year with the exception of the BASE simulation during winter, with the overestimation being most pronounced for BC AM3 during spring. The spread in monthly MDA8 ozone biases (i.e., model minus observation differences) between the four regional CMAQ simulations is on the order of $7-10 \mathrm{ppb}$ for most of the year at AQS sites, i.e., roughly $15-30 \%$ of simulated monthly mean values. The spread is smaller from June to September when it drops to less than $5 \mathrm{ppb}$. The spread in biases of domain-wide daily MDA8 ozone at AQS sites can reach as high as $15 \mathrm{ppb}$ during springtime. In contrast to the comparison of regional CMAQ and large-scale model results for aloft ozone in Sect. 3.2.2, the comparison of Fig. 11a and $\mathrm{b}$ shows that model performance for daytime average surface ozone mixing ratios at CASTNET monitors is not tightly linked between these two groups of simulations. This again indicates that while CMAQ free-tropospheric ozone mixing ratios are dominated by advection, other factors modulate surface ozone, including the treatment of vertical mixing, chemistry, deposition, and biogenic emissions. Moreover, the larger spread in model bias for the large-scale models compared to regional CMAQ can be explained by the fact that the large-scale models differ in their representation of many of these processes while the four regional CMAQ simulations share all input files and process representations and only differ in their representation of large-scale background concentrations. The comparison of Fig. 11a and b also illustrates that the biases of the regional CMAQ simulations are comparable to or lower than the biases of the large-scale models.

The bias time series in Fig. 11 considered spatial averages over all CASTNET or AQS monitors. To investigate spatial variations in these biases, Fig. 12 shows maps of seasonal mean biases for daytime average ozone at CASTNET sites for BASE, BC H-CMAQ, BC GEOS-Chem, and BC AM3 (rows 1 and 3) and C-IFS, H-CMAQ, GEOS-Chem, and AM3 (rows 2 and 4) for spring (rows 1 and 2) and summer (rows 3 and 4). These maps correspond to the time series shown in Fig. 11a-b. Two features stand out in these maps. First, all regional CMAQ simulations and correspond- 

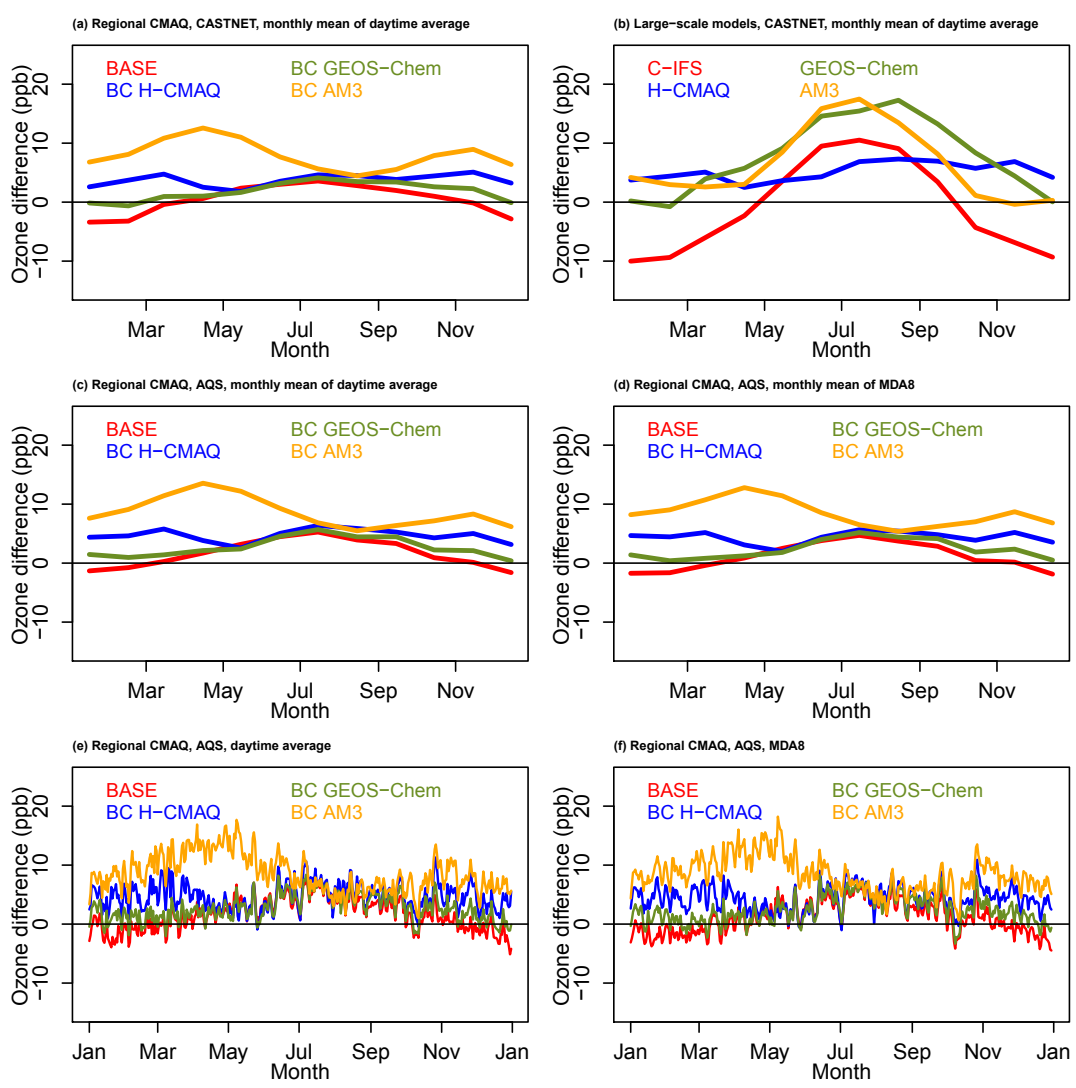

Figure 11. Time series of differences between modeled and observed ozone mixing ratios. (a) Monthly means of daytime average mixing ratios at CASTNET monitors for regional model simulations, panel (b) is the same as (a) but for large-scale models, panel (c) is the same as (a) but for AQS monitors, panel (d) is the same as (c) but for monthly means of MDA8 instead of monthly means of daytime average mixing ratios, panel (e) is the same as (c) but for daily daytime average mixing ratios, and panel (f) is the same as (d) but for daily MDA8.

ing large-scale simulations tend to be positively biased in the eastern United States during spring and summer; this is especially pronounced for C-IFS, GEOS-Chem, and AM3 during summer. Significant positive ozone biases at CASTNET sites in SE were also reported for GEOS-Chem for summer 2013 by Travis et al. (2016) who attributed a large portion of the bias to overestimated anthropogenic $\mathrm{NO}_{x}$ emissions. In the current study, the annual total anthropogenic $\mathrm{NO}_{x}$ emissions are shared across all regional- and large-scale simulations since the HTAP2 global inventory (Janssens-Maenhout et al., 2015) incorporated the AQMEII2 regional inventory (Pouliot et al., 2015) over North America, although differences may exist in terms of temporally and vertically allocating these emissions for a specific model. This suggests that factors other than anthropogenic emissions, such as biogenic emissions, chemistry, and deposition that differ between the large-scale models as well as between the largescale models and regional CMAQ, also affect the ozone bias in this region. Second, consistent with the time series shown in Fig. 11a-b, the model performance of the regional CMAQ simulation and the corresponding large-scale simulation is not tightly linked. As discussed above, this indicates that while free-tropospheric regional CMAQ ozone mixing ratios are dominated by advection, other factors including the treatment of vertical mixing, chemistry, deposition, and biogenic emissions modify surface ozone. However, despite the general differences between the regional CMAQ and large-scale model results, the bias patterns during spring and summer tend to be most similar between BC H-CMAQ and H-CMAQ compared to all other pairs of regional-/large-scale models, likely pointing to greater consistency in the treatment of physical and chemical processes across scales for this particular combination. It should be emphasized that the comparison of regional- and large-scale model biases in Figs. 11a-b and 12 is not aimed at establishing the relative merits of either modeling approach or of using one set of boundary conditions over another in the regional CMAQ simulations but rather at illustrating the magnitude of the impact of modeling choices on model performance.

Table $4 \mathrm{a}-\mathrm{c}$ present corresponding model performance metrics (NMB, NME, $R$ ) for MDA8 $\mathrm{O}_{3}$ at AQS monitors across the five analysis regions and four seasons for the four CMAQ simulations with different boundary conditions. Consistent with the results for the BASE simulations evaluated in 
Table 4. (a) NMB for MDA8 ozone at AQS sites for BASE, BC H-CMAQ, BC GEOS-Chem, and BC AM3. See the legend for Table 3 for a description on how the metrics were computed and for a definition of how different fonts are used in this table. (b) NME for MDA8 ozone at AQS sites for BASE, BC H-CMAQ, BC GEOS-Chem, and BC AM3. See the legend for Table 3 for a description on how the metrics were computed and for a definition of how different fonts are used in this table. (c) $R$ for MDA8 ozone at AQS sites for BASE, BC H-CMAQ, BC GEOS-Chem, and BC AM3. See the legend for Table 3 for a description on how the metrics were computed and for a definition of how different fonts are used in this table.

\begin{tabular}{|c|c|c|c|c|c|c|c|}
\hline (a) & & All & NW & IMW & MW & SE & $\mathrm{NE}$ \\
\hline \multirow[t]{4}{*}{ Spring } & BASE & 2.1 & 9.1 & 3.6 & 2.0 & 2.6 & -3.2 \\
\hline & BC H-CMAQ & 5.3 & 10.3 & 5.2 & 5.0 & 5.8 & 0.7 \\
\hline & BC GEOS-CHEM & 2.1 & 8.9 & 1.0 & 2.5 & 3.3 & -1.7 \\
\hline & BC AM3 & 18.6 & 31.6 & 23.4 & 18.2 & 14.8 & 16.2 \\
\hline \multirow[t]{4}{*}{ Summer } & BASE & 6.8 & 13.5 & -3.2 & 6.3 & 9.6 & 2.6 \\
\hline & BC H-CMAQ & 8.8 & 11.8 & 2.0 & 7.5 & 12.4 & 3.2 \\
\hline & BC GEOS-CHEM & 7.5 & 8.9 & -1.2 & 6.7 & 11.1 & 2.8 \\
\hline & BC AM3 & 11.4 & 23.0 & 2.9 & 10.6 & 12.1 & 8.4 \\
\hline \multirow[t]{4}{*}{ Fall } & BASE & 3.1 & 13.0 & 2.1 & 1.0 & 2.1 & 1.7 \\
\hline & BC H-CMAQ & 9.2 & 18.4 & 8.7 & 7.1 & 7.7 & 8.8 \\
\hline & BC GEOS-CHEM & 6.3 & 15.9 & 5.0 & 5.0 & 4.7 & 6.3 \\
\hline & BC AM3 & 13.3 & 30.4 & 12.3 & 13.7 & 10.7 & 15.1 \\
\hline \multirow[t]{4}{*}{ Winter } & BASE & -5.1 & 11.0 & -2.8 & -23.1 & -7.3 & -28.2 \\
\hline & BC H-CMAQ & 11.3 & 27.2 & 9.2 & 3.5 & 12.1 & 1.3 \\
\hline & BC GEOS-CHEM & 2.2 & 16.6 & 3.3 & -8.3 & 1.2 & -12.9 \\
\hline & BC AM3 & 18.4 & 36.4 & 19.6 & 13.5 & 17.9 & 12.1 \\
\hline (b) & & All & NW & IMW & MW & SE & $\mathrm{NE}$ \\
\hline \multirow[t]{4}{*}{ Spring } & BASE & 11.3 & 13.1 & 8.5 & 11.3 & 11.3 & 12.0 \\
\hline & BC HEMI & 12.1 & 13.3 & 10.6 & 11.9 & 11.7 & 11.6 \\
\hline & BC GEOS & 11.1 & 13.6 & 8.6 & 11.2 & 11.1 & 11.2 \\
\hline & BC AM3 & 20.2 & 31.6 & 23.7 & 20.1 & 17.1 & 18.9 \\
\hline \multirow[t]{4}{*}{ Summer } & BASE & 13.6 & 16.2 & 10.5 & 13.3 & 14.7 & 12.0 \\
\hline & BC HEMI & 14.9 & 15.4 & 11.4 & 14.6 & 16.3 & 13.2 \\
\hline & BC GEOS & 14.0 & 13.9 & 10.8 & 13.6 & 15.4 & 12.3 \\
\hline & BC AM3 & 16.0 & 24.7 & 13.8 & 15.2 & 16.1 & 13.8 \\
\hline \multirow[t]{4}{*}{ Fall } & BASE & 13.5 & 20.8 & 9.4 & 12.1 & 11.7 & 14.4 \\
\hline & BC HEMI & 15.2 & 22.0 & 12.2 & 14.2 & 13.2 & 16.1 \\
\hline & BC GEOS & 14.3 & 20.6 & 10.0 & 13.7 & 12.7 & 15.9 \\
\hline & BC AM3 & 17.9 & 30.5 & 14.5 & 18.1 & 14.6 & 20.0 \\
\hline \multirow[t]{4}{*}{ Winter } & BASE & 18.8 & 20.5 & 19.2 & 28.8 & 12.0 & 29.1 \\
\hline & BC HEMI & 17.4 & 30.5 & 18.0 & 15.9 & 15.1 & 14.4 \\
\hline & BC GEOS & 15.8 & 21.3 & 17.0 & 19.0 & 11.0 & 16.8 \\
\hline & BC AM3 & 21.2 & 38.7 & 22.7 & 18.0 & 19.4 & 15.5 \\
\hline (c) & & All & NW & IMW & MW & SE & $\mathrm{NE}$ \\
\hline \multirow[t]{4}{*}{ Spring } & BASE & 0.75 & 0.57 & 0.66 & 0.8 & 0.82 & 0.74 \\
\hline & BC HEMI & 0.72 & 0.59 & 0.55 & 0.8 & 0.82 & 0.72 \\
\hline & BC GEOS & 0.74 & 0.57 & 0.62 & 0.81 & 0.83 & 0.75 \\
\hline & BC AM3 & 0.63 & 0.45 & 0.6 & 0.65 & 0.77 & 0.59 \\
\hline \multirow[t]{4}{*}{ Summer } & BASE & 0.73 & 0.78 & 0.67 & 0.7 & 0.72 & 0.82 \\
\hline & BC HEMI & 0.72 & 0.78 & 0.67 & 0.68 & 0.71 & 0.8 \\
\hline & BC GEOS & 0.70 & 0.78 & 0.66 & 0.68 & 0.68 & 0.81 \\
\hline & BC AM3 & 0.71 & 0.64 & 0.56 & 0.69 & 0.72 & 0.79 \\
\hline \multirow[t]{4}{*}{ Fall } & BASE & 0.82 & 0.72 & 0.74 & 0.84 & 0.81 & 0.87 \\
\hline & BC HEMI & 0.80 & 0.71 & 0.72 & 0.81 & 0.81 & 0.86 \\
\hline & BC GEOS & 0.80 & 0.71 & 0.74 & 0.81 & 0.79 & 0.86 \\
\hline & BC AM3 & 0.77 & 0.67 & 0.59 & 0.75 & 0.8 & 0.83 \\
\hline \multirow[t]{4}{*}{ Winter } & BASE & 0.65 & 0.57 & 0.6 & 0.75 & 0.76 & 0.69 \\
\hline & BC HEMI & 0.67 & 0.71 & 0.63 & 0.75 & 0.71 & 0.7 \\
\hline & BC GEOS & 0.67 & 0.68 & 0.64 & 0.77 & 0.75 & 0.71 \\
\hline & BC AM3 & 0.68 & 0.71 & 0.64 & 0.78 & 0.72 & 0.73 \\
\hline
\end{tabular}



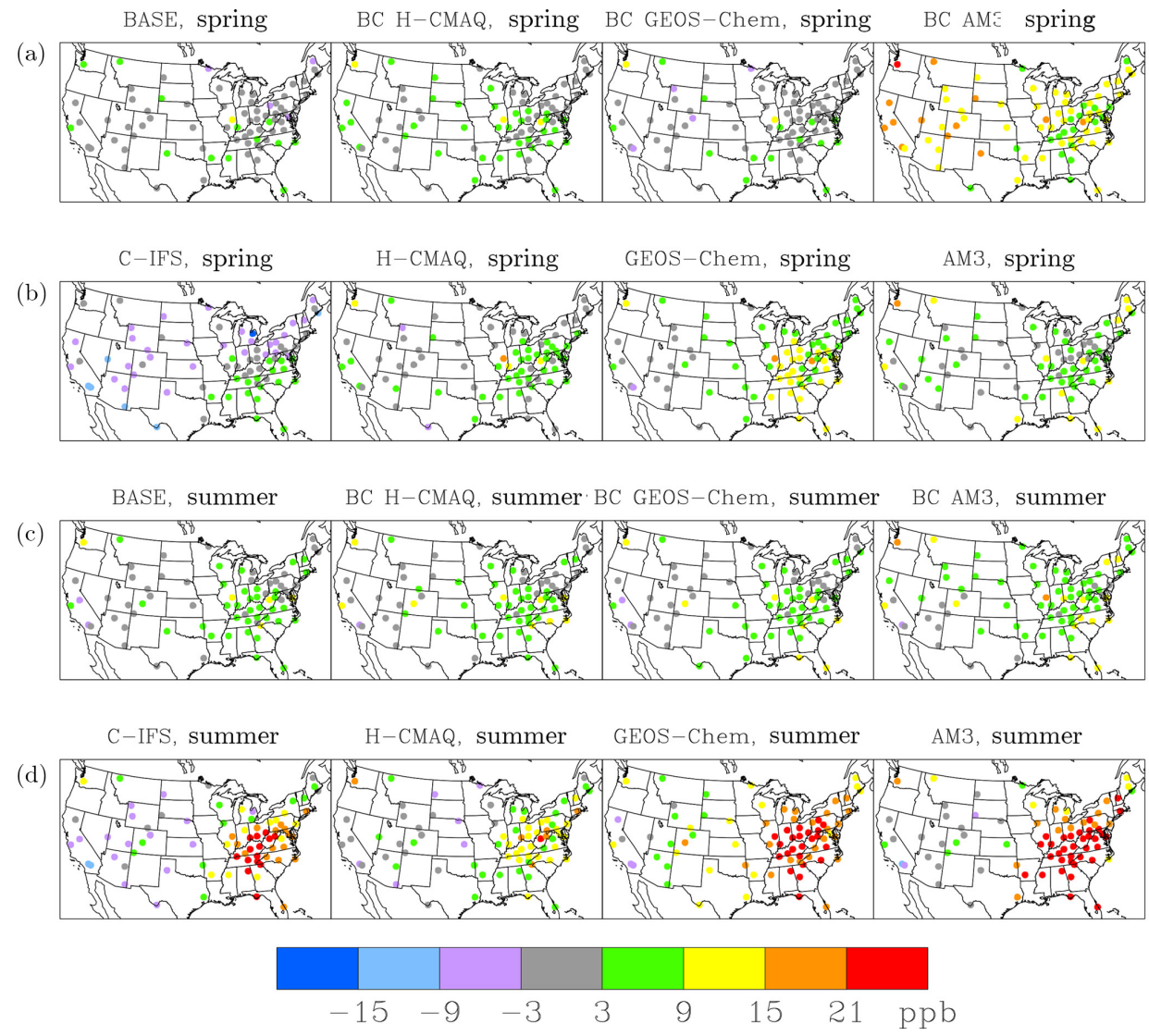

Figure 12. Map of seasonal mean bias for daytime average ozone at CASTNET sites for BASE, BC H-CMAQ, BC GEOS-Chem, and BC AM3 (a, c) and C-IFS, H-CMAQ, GEOS-Chem, and AM3 (b, d) for spring (a, b) and summer (c, d).

Table 3 in Sect. 3.1.1, model performance for all simulations tends to be worst in NW. However, the noteworthy feature of the results shown in Table $4 \mathrm{a}-\mathrm{c}$ is that boundary conditions can have a substantial impact on model performance as measured by the goals and acceptability criteria proposed by Emery et al. (2017). Boundary conditions also can affect conclusions about the directionality of the model bias. While wintertime $\mathrm{MDA} 8 \mathrm{O}_{3}$ is underestimated by the BASE run for all regions except $\mathrm{NW}$ as shown earlier, the opposite is true for the BC H-CMAQ and BC AM3 simulations. Regardless of whether or not these proposed model performance acceptability criteria will ultimately be adopted by the regional air quality model community, the results presented here show that the choice of lateral boundary conditions would be influential in measuring model performance against these acceptability criteria.

The results above assess the impact of different boundary conditions on model performance as measured across an entire season. Figure 13 shows paired-in-time CMAQobservation differences of MDA8 $\mathrm{O}_{3}$ at $\mathrm{AQS}$ monitors across the range of observed percentiles for each simulation, season, and region, analogous to the results shown in Fig. 3 for the BASE simulations. Overall, these graphs indicate that bound- ary conditions can affect model performance across the entire range of the observed distribution, although the impacts tend to be lower during summer and for the very highest observed percentiles. The results also reaffirm that the differences between the four simulations tend to be largest during winter and spring across all regions. During spring, most of the spread is caused by the higher MDA8 ozone values simulated by BC AM3 compared to the other three simulations across all regions. During summer, BC AM3 results are noticeably higher than results from the other three simulations only over the NW and NE regions. During fall, this is the case only for the NW region, while for the other four regions there is roughly equal spread between all simulations for all percentiles. During winter, when local production is small, the difference in lateral boundary conditions results in a clear separation between the four simulations across all regions and percentiles.

Corresponding paired-in-time results comparing daytime average $\mathrm{O}_{3}$ from the large-scale models and corresponding regional CMAQ simulations against observations at CASTNET monitors are presented in Figs. S3 and S4. The daytime average CMAQ results at CASTNET monitors in Fig. S4 are very similar to the MDA8 ozone results at AQS monitors 


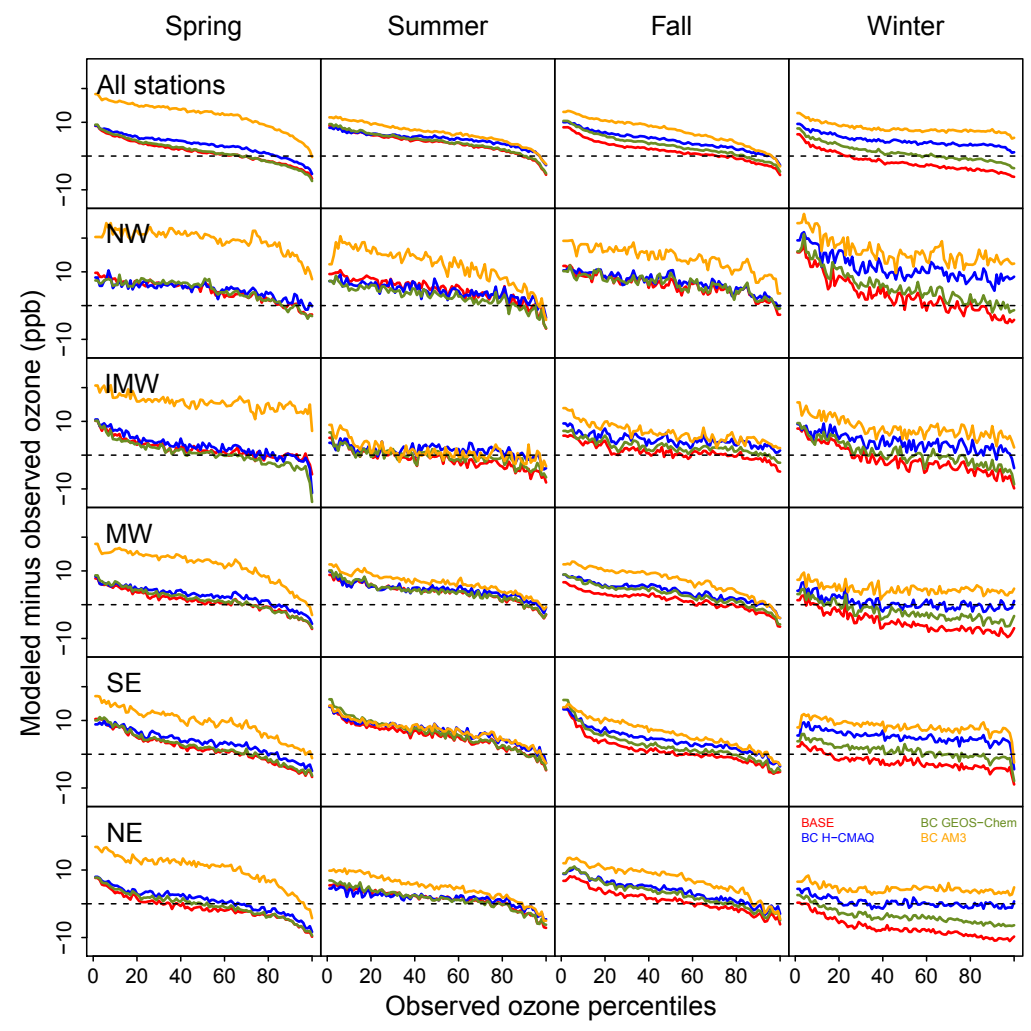

Figure 13. Paired-in-time differences between observed and modeled MDA8 ozone at AQS stations for each season and analysis region. Model results are for BASE (red), BC H-CMAQ (blue), BC GEOS-Chem (green), and BC AM3 (orange). For each season and region, the observed MDA8 ozone concentrations were rank ordered at each station. Next, differences between CMAQ simulations and observations were computed for each observed percentile by selecting the model value corresponding to the date of the observed percentile. Finally, the median value of these paired-in-time differences across all AQS stations in a given season and region was then computed for each observed percentile and is depicted in this figure.

shown in Fig. 13, consistent with the comparison of difference time series for different metrics and networks in Fig. 11. The spread in model-observation differences is larger for the large-scale models than the spread for the regional CMAQ results for most percentiles, seasons, and regions (note that the $y$-axis range for the large-scale model results in Fig. S3 is larger than the range for the CMAQ model results in Fig. S4). In contrast to the CMAQ results, which show a similar relative ranking of the four simulations for most seasons and regions (with BC AM3 generally having the highest modelto-observation differences, followed by $\mathrm{BC} \mathrm{H}-\mathrm{CMAQ}, \mathrm{BC}$ GEOS-Chem, and BASE), the performance of the four largescale models shows more variable behavior with no clear and systematic model-to-model differences across seasons and regions. This reaffirms that differences in free-tropospheric ozone at the boundary of regional simulations can have a systematic impact on such regional simulations throughout the domain while the effects of other model differences (e.g., transport, vertical mixing, chemistry, and deposition) manifest themselves in a spatially and temporally more complex manner. As a result, there is no clear similarity between sur- face ozone model performance for the large-scale models and the performance of the regional CMAQ simulations with the possible exception of the $\mathrm{H}-\mathrm{CMAQ} / \mathrm{BC} \mathrm{H}-\mathrm{CMAQ}$ pair which shares process representations across scales.

\section{Summary and discussion}

The results presented in this study are aimed at quantifying CMAQ-simulated regional-scale ozone burdens both near the surface and aloft, estimating process contributions to these burdens, and calculating the sensitivity of the simulated regional-scale ozone burden to several key model inputs with a particular emphasis on boundary conditions. The model simulations supporting this analysis were performed over the continental US for the year 2010 within the context of the AQMEII3/HTAP2 activities. Process analysis was employed to track the contributions of horizontal and vertical advection and diffusion, dry deposition, chemistry, and cloud processes on simulated ozone burdens. Changes in ozone mass in the upper layers were found to be dominated by advection. Advection also is the largest source of ozone for the column be- 
tween 250 and $750 \mathrm{mb}$ throughout most of the year, indicating that both lateral boundary conditions for this layer range and ozone in the upper layers (which in turn depends on lateral boundary conditions specified for the upper layers) have a profound impact on the burden simulated in the free troposphere. Chemistry and vertical mixing by convective clouds are the main sink for this column range. The ozone column below $750 \mathrm{mb}$ gains mass through the effects of chemistry especially during summer as well as through the effects of vertical mixing by convective clouds that tap into the ozone reservoir in the free troposphere to enhance the lower atmospheric ozone burden. The dominant sink term of ozone mass in this layer range is dry deposition at the surface. Advection and diffusion play a secondary role in modifying the domain-total ozone burden in this column range. These PA contributions to CMAQ-simulated ozone column burdens indicate that alternate model representation of advection, dry deposition, and cloud processes, as well as alternate model inputs (boundary conditions affecting advected ozone and emissions affecting ozone chemistry) would be expected to have noticeable effects on the simulated ozone burdens and their seasonal variation.

Hypothetical bounding scenarios were performed to quantify the effects of emissions, boundary conditions, and ozone dry deposition on the simulated ozone burden by zeroing out each of these factors in turn. Analysis of these simulations confirmed the key importance of boundary conditions which dominate over the other two factors for the free and upper troposphere and lower stratosphere. Ozone burdens below $750 \mathrm{mb}$ and especially ozone mixing ratios at the surface show significant changes in the no-emissions and noozone dry deposition simulations, and the relative impact of all three bounding simulations on surface ozone varies seasonally and spatially. Overall, the analysis of the brute-force sensitivity simulations confirms that the characterization of ozone outside the regional-scale modeling domain can have a profound impact on simulated regional-scale ozone.

Four global and hemispheric modeling systems, i.e., CIFS, H-CMAQ, GEOS-Chem, and AM3, were used to derive alternate boundary conditions for the regional-scale CMAQ simulations. When comparing ozone from these four largescale models against each other along the boundaries of the regional-scale CMAQ domain, noticeable differences were found both in terms of the magnitude and seasonal variations of ozone mixing ratios. GEOS-Chem and C-IFS simulated the highest ozone mixing ratio in the stratosphere while AM3 generally simulated the largest ozone mixing ratio in the free troposphere and planetary boundary layer (PBL). Model-tomodel differences in the magnitude and seasonal variations of ozone mixing ratios along the regional model boundaries in the mid-troposphere point to differences in the representation of stratospheric ozone and stratosphere-troposphere exchange processes in the large-scale models.

The regional-scale CMAQ simulations using these four different boundary conditions showed that the largest ozone abundance in the upper layers was simulated by BC GEOSChem, followed by BASE (using C-IFS lateral boundary conditions), $\mathrm{BC} \mathrm{AM} 3$, and $\mathrm{BC}$ H-CMAQ, consistent with the analysis of the ozone fields from the large-scale models along the CMAQ boundaries and with the notion that the stratospheric ozone burden simulated by regional-scale CMAQ is driven by advection of lateral boundary conditions. The most notable feature for the ozone column mass in the mid-troposphere was found to be the larger springtime ozone burden simulated by BC AM3 compared to the other three simulations, again consistent with the analysis of the ozone boundary conditions in that layer range. The same feature was also found for the ozone column mass closer to the surface, which confirms the notion that vertical exchange between this layer range and the free troposphere leads to a tight coupling of their ozone fluctuations. For all layer ranges, the analysis of these regional-scale CMAQ simulations highlighted that differences in ozone boundary conditions result in differences of CMAQ-simulated ozone column mass over the modeling domain.

The results for surface ozone mixing ratios are consistent with the results for the free-tropospheric and lowertropospheric/PBL ozone burdens. In particular, the largest differences between the four sets of simulations exist between the BC AM3 and BASE simulations and are especially pronounced during spring and winter where they can reach more than $10 \mathrm{ppb}$ for seasonal mean ozone mixing ratios and as much as $15 \mathrm{ppb}$ for domain-averaged MDA8 ozone on individual days. In contrast, the differences between $\mathrm{BC} \mathrm{H}-$ CMAQ and BASE and BC GEOS-Chem and BASE are typically smaller ( $\pm 4 \mathrm{ppb}$ for most of the modeling domain except for BC H-CMAQ during winter). Comparing simulated surface ozone mixing ratios to observations and computing seasonal and regional model performance statistics revealed that boundary conditions can have a substantial impact on model performance and can also affect conclusions on the directionality of model biases. Further analysis showed that boundary conditions can affect model performance across the entire range of the observed distribution, although the impacts tend to be lower during summer and for the very highest observed percentiles.

While the results presented in this paper highlight the importance of boundary conditions for regional-scale ozone simulations, it should be noted that they were based on a single year of simulations. Many previous studies have shown a strong connection between interannual meteorological variability and ozone on continental-to-global scales (Lin et al., 2012a, b, 2017; Hegarty et al., 2007; Porter et al., 2017; Hogrefe et al., 2011), especially as it relates to the impacts of variations in hemispheric-scale ozone on regional-scale ozone. Future work analyzing multi-year simulations from multiple global models linked to corresponding regionalscale simulations would be beneficial in better constraining the effects of large-scale interannual variability on simulated regional-scale ozone burdens and the interannual variability 
of contributions from large-scale ozone to surface ozone especially during time periods of elevated concentrations.

The results shown in Sect. 3 (e.g., Figs. 8-9) strongly suggest that differences in the mid-tropospheric ozone mixing ratios simulated by the large-scale models were the main driver of ozone differences between the corresponding regional-scale CMAQ simulations. However, differences in other species such as PAN, differences in the availability of a complete set of CMAQ species from all large-scale models (see Table 1), and inconsistencies in chemical speciation between the large-scale models and regional-scale CMAQ may also have contributed to the ozone differences between the regional-scale CMAQ simulations. Thus, while linking output from available global or hemispheric models to regionalscale models despite such differences represents the current best practices in the regional-scale air quality modeling community, additional research should be geared towards developing modeling frameworks that enable a consistent representation of model processes, species, and vertical grid representation across scales. An example of such efforts is the ongoing work to extend CMAQ to hemispheric scales (Mathur et al., 2017). Ensuring such consistency does not in itself guarantee improved model performance but would allow for more targeted diagnostic model evaluation aimed at specific processes which is more challenging when linking together different modeling systems. To achieve such consistency, future work should also be directed toward developing and implementing scale-dependent treatment for atmospheric chemistry in next-generation global dynamic models with variable grid-resolution features such as the Model for Prediction Across Scales (MPAS) (Skamarock et al., 2012) and the Finite-Volume Cubed-Sphere Dynamical Core (FV3) model (Harris and Lin, 2013). Finally, the results from the bounding sensitivity simulations suggest that coordinated evaluation and intercomparison activities for ozone dry deposition would be valuable in better constraining simulated ozone budgets.

In addition to these potential future research directions for the global- and regional-scale air quality modeling communities, there are also several more concrete opportunities for further analyses that could be pursued as part of the current collaboration between AQMEII and TF-HTAP. First, while the present study shows that different boundary conditions can have an impact across the entire range of modeled ozone mixing ratios, it does not analyze such impacts during specific events and at specific locations. Such case study analyses could be the topic of future work. Second, the CMAQ PA results indicate the importance of vertical mixing processes (including mixing by convective clouds), advection, and dry deposition on the modeled vertical distribution of ozone. Inert tracers of boundary conditions included in the AQMEII3 simulations analyzed by Solazzo et al. (2017a) can aid in the diagnosis of how model-to-model differences in these processes affect the impact of boundary conditions on ozone simulated by different regional-scale models (Liu et al., 2018). Finally, the EM ZERO bounding simulation could be further analyzed in the context of estimating North American background (NAB) (Fiore et al., 2014) or US background (USB) (Dolwick et al., 2015) ozone, especially if this bounding simulation were to be repeated with lateral boundary conditions derived from H-CMAQ, GEOS-Chem, and AM3 instead of C-IFS. However, even without such additional runs, the results from the simulations with different boundary conditions performed for base emission conditions suggest that estimated NAB or USB values resulting from such potential simulations would vary by as much as $10 \mathrm{ppb}$ on a seasonal mean basis since chemical destruction of boundary conditions in the base emissions scenario used in this study likely acts to reduce the degree to which ozone differences at the boundaries can influence surface ozone simulated within the regional-scale CMAQ domain. The effect of this chemical destruction of boundary ozone on estimated boundary contributions to surface ozone under a base emissions scenario has been quantified by Baker et al. (2015). Such an expected range of up to $10 \mathrm{ppb}$ in CMAQ-estimated seasonal mean NAB or USB values resulting from the use of boundary conditions derived from the four different large-scale models used in the present study would be consistent with the differences in NAB estimates reported by Fiore et al. (2014) that were derived from GEOS-Chem and AM3 applied for 2006.

Code availability. Source code for version 5.0.2 of the CMAQ modeling system can be downloaded from https://github.com/ USEPA/CMAQ/tree/5.0.2. For further information, please visit the US Environmental Protection Agency website for the CMAQ system: https://www.epa.gov/cmaq.

Data availability. Data used to generate figures and tables shown in this article can be downloaded at https://edg.epa.gov/metadata/ catalog/main/home.page. Raw model outputs are available on request from the corresponding author. Observational data sets used in the analyses presented in this paper are available from their respective websites: https://aqs.epa.gov/aqsweb/airdata/download_files. html (AQS); https://www.epa.gov/castnet (CASTNET); https:// woudc.org/home.php (WOUDC); https://www.esrl.noaa.gov/gmd/ ozwv/ozsondes/ (NOAA ESRL). Last access: 8 March 2018.

\section{The Supplement related to this article is available online at https://doi.org/10.5194/acp-18-3839-2018-supplement.}

Competing interests. The authors declare that they have no conflict of interest. 
Disclaimer. The views expressed in this paper are those of the authors and do not necessarily represent the view or policies of the US Environmental Protection Agency.

Special issue statement. This article is part of the special issue "Global and regional assessment of intercontinental transport of air pollution: results from HTAP, AQMEII and MICS". It is not associated with a conference.

Acknowledgements. We gratefully acknowledge AQMEII and TF-HTAP for facilitating the analysis described in the manuscript by designing and coordinating internally consistent global- and regional-scale air quality model simulations. Rokjin J. Park was supported by the National Strategic Project - Fine particle of the National Research Foundation of Korea (NRF) funded by the Ministry of Science and ICT (MSIT), the Ministry of Environment (ME), and the Ministry of Health and Welfare (MOHW) (NRF-2017M3D8A1090670). We also thank the maintainers of the AQS and CASTNET data portals from which the surface ozone observations used in this study were obtained. Finally, we would like to acknowledge NOAA ESRL for making available the ozonesonde measurements at Trinidad Head, Boulder, and Huntsville, and the World Ozone and UV Data Center for making available the ozonesonde measurements at Edmonton, Churchill, and Wallops Island.

Edited by: Frank Dentener

Reviewed by: two anonymous referees

\section{References}

Appel, K. W., Napelenok, S. L., Foley, K. M., Pye, H. O. T., Hogrefe, C., Luecken, D. J., Bash, J. O., Roselle, S. J., Pleim, J. E., Foroutan, H., Hutzell, W. T., Pouliot, G. A., Sarwar, G., Fahey, K. M., Gantt, B., Gilliam, R. C., Heath, N. K., Kang, D., Mathur, R., Schwede, D. B., Spero, T. L., Wong, D. C., and Young, J. O.: Description and evaluation of the Community Multiscale Air Quality (CMAQ) modeling system version 5.1, Geosci. Model Dev., 10, 1703-1732, https://doi.org/10.5194/gmd-10-1703-2017, 2017.

Baker, K. R., Emery, C., Dolwick, P., and Yarwood, G.: Photochemical grid model estimates of lateral boundary contributions to ozone and particulate matter across the continental United States, Atmos. Environ., 123, 49-62, https://doi.org/10.1016/j.atmosenv.2015.10.055, 2015.

Bey, I., Jacob, D. J., Yantosca, R. M., Logan, J. A., Field, B., Fiore, A. M., Li, Q., Liu, H., Mickley, L. J., and Schultz, M.: Global modeling of tropospheric chemistry with assimilated meteorology: Model description and evaluation, J. Geophys. Res., 106, 23073-23096, 2001.

Byun, D. W. and Ching, J. K. S.: Science Algorithms of the EPA MODELS-3 Community Multiscale Air Quality (CMAQ) Modelling System, US Environmental Protection Agency, Washington, D.C., EPA/600/R-99/030(NTIS PB2000-100561), 1999.

Byun, D. W. and Schere, K. L.: Review of the governing equations, computational algorithms, and other components of the Models-
3 Community Multiscale Air Quality (CMAQ) Modeling System, Appl. Mech. Rev., 59, 51-77, 2006.

Chapman, E. G., Gustafson Jr., W. I., Easter, R. C., Barnard, J. C., Ghan, S. J., Pekour, M. S., and Fast, J. D.: Coupling aerosol-cloud-radiative processes in the WRF-Chem model: Investigating the radiative impact of elevated point sources, Atmos. Chem. Phys., 9, 945-964, https://doi.org/10.5194/acp-9945-2009, 2009.

Cooper, O. R., Carmichael, G., Dong, X., Emmons, L., Fu, J., Flemming, J., Henze, D., Hogrefe, C., Huang, M., Lenzen, A., Lin, M., Park, R., Pierce, R. B., Sudo, K., and Wang, Y.: A comparison of global and regional-scale chemistry model simulations of western North America baseline ozone, Atmos. Chem. Phys. Discuss., in preparation, 2018.

Dolwick, P., Akhtar, F., Baker, K. R., Possiel, N., Simon, H., and Tonnesen, G.: Comparison of background ozone estimates over the western United States based on two separate model methodologies, Atmos. Environ., 109, 282-296, https://doi.org/10.1016/j.atmosenv.2015.01.005, 2015.

Donner, L. J., Wyman, B. L., Hemler, R. S., Horowitz, L. W., Ming, Y., Zhao, M., Golaz, J.-C., Ginoux, P., Lin, S.-J., Schwarzkopf, M. D., Austin, J., Alaka, G., Cooke, W. F., Delworth, T. L., Freidenreich, S. M., Gordon, C. T., Griffies, S. M., Held, I. M., Hurlin, W. J., Klein, S. A., Knutson, T. R., Langenhorst, A. R., Lee, H.-C., Lin, Y., Magi, B. I., Malyshev, S. L., Milly, P. C. D., Naik, V., Nath, M. J., Pincus, R., Ploshay, J. J., Ramaswamy, V., Seman, C. J., Shevliakova, E., Sirutis, J. J., Stern, W. F., Stouffer, R. J., Wilson, R. J., Winton, M., Wittenberg, A. T., and Zeng, F.: The Dynamical Core, Physical Parameterizations, and Basic Simulation Characteristics of the Atmospheric Component AM3 of the GFDL Global Coupled Model CM3, J. Climate, 24, 34843519, https://doi.org/10.1175/2011jcli3955.1, 2011.

Emery, C., L. Zhen, A., Russell, G., Odman, M. T., Yarwood, G., and Kumar, N.: Recommendations on statistics and benchmarks to assess photochemical model performance, J. Air Waste Manage., 67, 582-598, https://doi.org/10.1080/10962247.2016.1265027, 2017.

Emmons, L. K., Walters, S., Hess, P. G., Lamarque, J.-F., Pfister, G. G., Fillmore, D., Granier, C., Guenther, A., Kinnison, D., Laepple, T., Orlando, J., Tie, X., Tyndall, G., Wiedinmyer, C., Baughcum, S. L., and Kloster, S.: Description and evaluation of the Model for Ozone and Related chemical Tracers, version 4 (MOZART-4), Geosci. Model Dev., 3, 43-67, https://doi.org/10.5194/gmd-3-43-2010, 2010.

Environ: CAMx (Comprehensive Air Quality Model with Extensions) User's Guide Version 6.1 ENVIRON International Corporation, Novato, CA, 2014.

European Commission: Joint Research Centre (JRC)/Netherlands Environmental Assessment Agency (PBL), Emission Database for Global Atmospheric Research (EDGAR), release version 4.2, available at: http://edgar.jrc.ec.europa.eu/overview.php?v= 42 (last access: 8 January 2018), 2011.

Fiore, A. M., Dentener, F. J., Wild, O., Cuvelier, C., Schultz, M. G., Hess, P., Textor, C., Schulz, M., Doherty, R. M., Horowitz, L. W., MacKenzie, I. A., Sanderson, M. G., Shindell, D., Stevenson, D. S., Szopa, S., Van Dingenen, R., Zeng, G., Atherton, C., Bergmann, D. J., Bey, I., Carmichael, G., Collins, W. J., Duncan, B., Faluvegi, G., Folberth, G., Gauss, M., Gong, S., Hauglustaine, D., Holloway, T., Isaksen, I. S. A., Jacob, D., Jon- 
son, J. E., Kaminski, J. W., Keating, T. J., Lupu, A., Marmer, E., Montanaro, V., Park, R. J., Pitari, G., Pringle, K. J., Pyle, J. A., Schroeder, S., Vivanco, M. G., Wind, P., Wojcik, G., Wu, S., and Zuber, A.: Multimodel estimates of intercontinental sourcereceptor relationships for ozone pollution, J. Geophys. Res., 114, D04301, https://doi.org/10.1029/2008jd010816, 2009.

Fiore, A. M., Oberman, J. T., Lin, M. Y., Zhang, L., Clifton, O. E., Jacob, D. J., Naik, V., Horowitz, L. W., Pinto, J. P., and Milly, G. P.: Estimating North American background ozone in U.S. surface air with two independent global models: Variability, uncertainties, and recommendations, Atmos. Environ., 96, 284-300, https://doi.org/10.1016/j.atmosenv.2014.07.045, 2014.

Flemming, J., Huijnen, V., Arteta, J., Bechtold, P., Beljaars, A., Blechschmidt, A.-M., Diamantakis, M., Engelen, R. J., Gaudel, A., Inness, A., Jones, L., Josse, B., Katragkou, E., Marecal, V., Peuch, V.-H., Richter, A., Schultz, M. G., Stein, O., and Tsikerdekis, A.: Tropospheric chemistry in the Integrated Forecasting System of ECMWF, Geosci. Model Dev., 8, 975-1003, https://doi.org/10.5194/gmd-8-975-2015, 2015.

Flemming, J., Benedetti, A., Inness, A., Engelen, R. J., Jones, L., Huijnen, V., Remy, S., Parrington, M., Suttie, M., Bozzo, A., Peuch, V.-H., Akritidis, D., and Katragkou, E.: The CAMS interim Reanalysis of Carbon Monoxide, Ozone and Aerosol for 2003-2015, Atmos. Chem. Phys., 17, 1945-1983, https://doi.org/10.5194/acp-17-1945-2017, 2017.

Galmarini, S., Koffi, B., Solazzo, E., Keating, T., Hogrefe, C., Schulz, M., Benedictow, A., Griesfeller, J. J., JanssensMaenhout, G., Carmichael, G., Fu, J., and Dentener, F.: Technical note: Coordination and harmonization of the multi-scale, multi-model activities HTAP2, AQMEII3, and MICS-Asia3: simulations, emission inventories, boundary conditions, and model output formats, Atmos. Chem. Phys., 17, 1543-1555, https://doi.org/10.5194/acp-17-1543-2017, 2017.

Guenther, A., Hewitt, C. N., Erickson, D., Fall, R., Geron, C., Graedel, T., Harley, P., Klinger, L., Lerdau, M., McKay, W. A., Pierce, T., Scholes, B., Steinbrecher, R., Tallamraju, R., Taylor, J., and Zimmerman, P.: A Global Model of Natural Volatile Organic Compound Emissions, J. Geophys. Res., 100, 8873-8892, 1995.

Guenther, A., Karl, T., Harley, P., Wiedinmyer, C., Palmer, P. I., and Geron, C.: Estimates of global terrestrial isoprene emissions using MEGAN (Model of Emissions of Gases and Aerosols from Nature), Atmos. Chem. Phys., 6, 3181-3210, https://doi.org/10.5194/acp-6-3181-2006, 2006.

Harley, R. A., Russell, A. G., McRae, G. J., Cass, G., and Seinfeld, J. H.: Photochemical modeling of the Southern California air quality study, Environ. Sci. Technol., 27, 378-388, https://doi.org/10.1021/es00039a019, 1993.

Harris, L. M. and Lin, S.-J.: A two-way nested global-regional dynamical core on the cubed-sphere grid, Mon. Weather Rev., 141, 283-306, https://doi.org/10.1175/MWR-D-11-00201.1, 2013.

Hegarty, J., Mao, H., and Talbot, R.: Synoptic controls on summertime surface ozone in the northeastern United States, J. Geophys. Res., 112, D14306, https://doi.org/10.1029/2006JD008170, 2007.

Henderson, B. H., Akhtar, F., Pye, H. O. T., Napelenok, S. L., and Hutzell, W. T.: A database and tool for boundary conditions for regional air quality modeling: description and evaluation,
Geosci. Model Dev., 7, 339-360, https://doi.org/10.5194/gmd-7339-2014, 2014.

Hogrefe, C., Hao, W., Zalewsky, E. E., Ku, J.-Y., Lynn, B., Rosenzweig, C., Schultz, M. G., Rast, S., Newchurch, M. J., Wang, L., Kinney, P. L., and Sistla, G.: An analysis of long-term regional-scale ozone simulations over the Northeastern United States: variability and trends, Atmos. Chem. Phys., 11, 567-582, https://doi.org/10.5194/acp-11-567-2011, 2011.

Hogrefe, C., Roselle, S. J., and Bash, J. O.: Persistence of initial conditions in continental scale air quality simulations, Atmos. Environ., 160, 36-45, 2017.

Holloway, T., Fiore, A., and Hastings, M. G.: Intercontinental transport of air pollution: will emerging science lead to a new hemispheric treaty?, Environ. Sci. Technol., 37, 4535-4542, 2003.

Horowitz, L. W., Walters, S., Mauzerall, D. L., Emmons, L. K., Rasch, P. J., Granier, C., Tie, X., Lamarque, J. F., Schultz, M. G., Tyndall, G. S., Orlando, J. J., and Brasseur, G. P.: A global simulation of tropospheric ozone and related tracers: Description and evaluation of MOZART, version 2, J. Geophys. Res., 108, 4784, https://doi.org/10.1029/2002JD002853, 2003.

Huang, M., Carmichael, G. R., Pierce, R. B., Jo, D. S., Park, R. J., Flemming, J., Emmons, L. K., Bowman, K. W., Henze, D. K., Davila, Y., Sudo, K., Jonson, J. E., Tronstad Lund, M., Janssens-Maenhout, G., Dentener, F. J., Keating, T. J., Oetjen, H., and Payne, V. H.: Impact of intercontinental pollution transport on North American ozone air pollution: an HTAP phase 2 multi-model study, Atmos. Chem. Phys., 17, 5721-5750, https://doi.org/10.5194/acp-17-5721-2017, 2017.

Im, U., Bianconi, R., Solazzo, E., Kioutsioukis, I., Badia, A., Balzarini, A., Baró, R., Bellasio, R., Brunner, D., Chemel, C., Curci, G., Flemming, J., Forkel, R., Giordano, L., JiménezGuerrero, P., Hirtl, M., Hodzic, A., Honzak, L., Jorba, O., Knote, C., Kuenen, J. J. P., Makar, P. A., Manders-Groot, A., Neal, L., Pérez, J. L., Pirovano, G., Pouliot, G., San Jose, R., Savage, N., Schroder, W., Sokhi, R. S., Syrakov, D., Torian, A., Tuccella, P., Werhahn, J., Wolke, R., Yahya, K., Zabkar, R., Zhang, Y., Zhang, J., Hogrefe, C., and Galmarini, S.: Evaluation of operational on-line-coupled regional air quality models over Europe and North America in the context of AQMEII phase 2. Part I: Ozone, Atmos. Environ., 115, 404-420, https://doi.org/10.1016/j.atmosenv.2014.09.042, 2015a.

Im, U., Bianconi, R., Solazzo, E., Kioutsioukis, I., Badia, A., Balzarini, A., Baró, R., Bellasio, R., Brunner, D., Chemel, C., Curci, G., van der Gon, H. D., Flemming, J., Forkel, R., Giordano, L., Jiménez-Guerrero, P., Hirtl, M., Hodzic, A., Honzak, L., Jorba, O., Knote, C., Makar, P. A., Manders-Groot, A., Neal, L., Pérez, J. L., Pirovano, G., Pouliot, G., San Jose, R., Savage, N., Schroder, W., Sokhi, R. S., Syrakov, D., Torian, A., Tuccella, P., Wang, K., Werhahn, J., Wolke, R., Zabkar, R., Zhang, Y., Zhang, J., Hogrefe, C., and Galmarini, S.: Evaluation of operational online-coupled regional air quality models over Europe and North America in the context of AQMEII phase 2. Part II: Particulate matter, Atmos. Environ., 115, 421-441, https://doi.org/10.1016/j.atmosenv.2014.08.072, 2015 b.

Jacob, D. J., Logan, J. A., and Murti, P. P.: Effect of rising Asian emissions on surface ozone in the United States, Geophys. Res. Lett., 26, 2175-2178, 1999.

Jang, J.-C. C., Jeffries, H. E., Byun, D., and Pleim, J. E.: Sensitivity of ozone to model grid resolution - I. Application of high- 
resolution regional acid deposition model, Atmos. Environ., 29, 3085-3100, 1995.

Janssens-Maenhout, G., Crippa, M., Guizzardi, D., Dentener, F., Muntean, M., Pouliot, G., Keating, T., Zhang, Q., Kurokawa, J., Wankmüller, R., Denier van der Gon, H., Kuenen, J. J. P., Klimont, Z., Frost, G., Darras, S., Koffi, B., and Li, M.: HTAP_v2.2: a mosaic of regional and global emission grid maps for 2008 and 2010 to study hemispheric transport of air pollution, Atmos. Chem. Phys., 15, 11411-11432, https://doi.org/10.5194/acp-15-11411-2015, 2015.

Jeffries, H. and Tonnesen, S.: A comparison of two photochemical reaction mechanisms using mass balance and process analysis, Atmos. Environ., 28, 2991-3003, 1994.

Kaiser, J. W., Heil, A., Andreae, M. O., Benedetti, A., Chubarova, N., Jones, L., Morcrette, J.-J., Razinger, M., Schultz, M. G., Suttie, M., and van der Werf, G. R.: Biomass burning emissions estimated with a global fire assimilation system based on observed fire radiative power, Biogeosciences, 9, 527-554, https://doi.org/10.5194/bg-9-527-2012, 2012.

Li, Q. B., Jacob, D. J., Bey, I., Palmer, P. I., Duncan, B. N., Field, B. D., Martin, R. V., Fiore, A. M., Yantosca, R. M., Parrish, D. D., Simmonds, P. G., and Oltmans, S. J.: Transatlantic transport of pollution and its effects on surface ozone in Europe and North America, J. Geophys. Res., 107, D001422, https://doi.org/10.1029/2001JD001422, 2002.

Lin, M., Holloway, T., Oki, T., Streets, D. G., and Richter, A.: Multiscale model analysis of boundary layer ozone over East Asia, Atmos. Chem. Phys., 9, 3277-3301, https://doi.org/10.5194/acp9-3277-2009, 2009.

Lin, M., Fiore, A. M., Cooper, O. R., Horowitz, L. W., Langford, A. O., Levy, H., Johnson, B. J., Naik, V., Oltmans, S. J., and Senff, C. J.: Springtime high surface ozone events over the western United States: Quantifying the role of stratospheric intrusions, J. Geophys. Res., 117, D00V22, https://doi.org/10.1029/2012jd018151, 2012a.

Lin, M., Fiore, A. M., Horowitz, L. W., Cooper, O. R., Naik, V., Holloway, J., Johnson, B. J., Middlebrook, A. M., Oltmans, S. J., Pollack, I. B., Ryerson, T. B., Warner, J. X., Wiedinmyer, C., Wilson, J., and Wyman, B.: Transport of Asian ozone pollution into surface air over the western United States in spring, J. Geophys. Res., 117, D00V07, https://doi.org/10.1029/2011jd016961, 2012b.

Lin, M., Horowitz, L. W., Cooper, O. R., Tarasick, D., Conley, S., Iraci, L. T., Johnson, B., Leblanc, T., Petropavlovskikh, I., and Yates, E. L.: Revisiting the evidence of increasing springtime ozone mixing ratios in the free troposphere over western North America, Geophys. Res. Lett., 42, 8719-8728, https://doi.org/10.1002/2015GL065311, 2015.

Lin, M., Horowitz, L. W., Payton, R., Fiore, A. M., and Tonnesen, G.: US surface ozone trends and extremes from 1980 to 2014: quantifying the roles of rising Asian emissions, domestic controls, wildfires, and climate, Atmos. Chem. Phys., 17, 29432970, https://doi.org/10.5194/acp-17-2943-2017, 2017.

Liu, P., Hogrefe, C., Im, U., Bieser, J., Mathur, R., Nopmongcol, U., Roselle, S., and Spero, T.: Multi-model Comparison of Lateral Boundary Contributions to Surface Ozone over the United States, Atmos. Chem. Phys. Discuss., in press, 2018.

Mathur, R., Xing, J., Gilliam, R., Sarwar, G., Hogrefe, C., Pleim, J., Pouliot, G., Roselle, S., Spero, T. L., Wong, D. C., and
Young, J.: Extending the Community Multiscale Air Quality (CMAQ) modeling system to hemispheric scales: overview of process considerations and initial applications, Atmos. Chem. Phys., 17, 12449-12474, https://doi.org/10.5194/acp-17-124492017, 2017.

McRae, G. J. and Seinfeld, J. H.: Development of a secondgeneration mathematical model for urban air pollution - II. Evaluation of model performance, Atmos. Environ., 17, 501-522, https://doi.org/10.1016/0004-6981(83)90124-5, 1983.

Meijer, E. W., van Velthoven, P. F. J., Brunner, D. W., Huntrieser, H., and Kelder, H.: Improvement and evaluation of the parameterization of nitrogen oxide production by lightning, Phys. Chem. Earth Pt. C, 26, 577-583, 2001.

Murray, L. T., Jacob, D. J., Logan, J. A., Hudman, R. C., and Koshak, W. J.: Optimized regional and inter-annual variability of lightning in a global chemical transport model constrained by LIS/OTD satellite data, J. Geophys. Res., 117, D20307, https://doi.org/10.1029/2012JD017934, 2012.

Pierce, T., Geron, C., Bender, L., Dennis, R., Tonnesen, G., and Guenther, A.: Influence of Increased Isoprene Emissions on Regional Ozone Modeling, J. Geophys. Res., 103, 25611-25629, 1998.

Porter, P. S., Rao, S. T., Hogrefe, C., and Mathur, R.: A reduced form model for ozone based on two decades of CMAQ simulations for the continental United States, Atmos. Poll. Res., 8, 275-284, https://doi.org/10.1016/j.apr.2016.09.005, 2017.

Pouliot, G., van der Gon, H. A. C. D., Kuenen, J., Zhang, J., Moran, M. D., and Makar, P. A.: Analysis of the emission inventories and model-ready emission datasets of Europe and North America for phase 2 of the AQMEII project, Atmos. Environ., 115, 345-360, https://doi.org/10.1016/j.atmosenv.2014.10.061, 2015.

Price, C., Penner, J., and Prather, M.: $\mathrm{NO}_{x}$ from lightning 1: Global distribution based on lightning physics, J. Geophys. Res., 102, 5929-5941, 1997.

Randerson, J. T., van der Werf, G. R., Giglio, L., Collatz, G. J., and Kasibhatla, P. S.: Global Fire Emissions Database, Version 3 (GFEDv3.1), Data set, Oak Ridge National Laboratory Distributed Active Archive Center, Oak Ridge, Tennessee, USA, https://doi.org/10.3334/ORNLDAAC/1191, 2013.

Rao, S. T., Galmarini, S., and Pucket, K.: Air Quality Model Evaluation International Initiative (AQMEII): Advancing the State of the Science in Regional Photochemical Modeling and Its Applications, B. Am. Meteorol. Soc., 92, 23-30, https://doi.org/10.1175/2010BAMS3069.1, 2011.

Reidmiller, D. R., Fiore, A. M., Jaffe, D. A., Bergmann, D., Cuvelier, C., Dentener, F. J., Duncan, B. N., Folberth, G., Gauss, M., Gong, S., Hess, P., Jonson, J. E., Keating, T., Lupu, A., Marmer, E., Park, R., Schultz, M. G., Shindell, D. T., Szopa, S., Vivanco, M. G., Wild, O., and Zuber, A.: The influence of foreign vs. North American emissions on surface ozone in the US, Atmos. Chem. Phys., 9, 5027-5042, https://doi.org/10.5194/acp-9-50272009, 2009.

Schere, K., Flemming, J., Vautard, R., Chemel, C., Colette, A., Hogrefe, C., Bessagnet, B., Meleux, F., Mathur, R., Roselle, S., Hu, R.-M., Sokhi, R. S., Rao, S. T., and Galmarini, S.: Trace gas/aerosol boundary concentrations and their impacts on continental-scale AQMEII modeling domains, Atmos. Environ., 53, 38-50, https://doi.org/10.1016/j.atmosenv.2011.09.043, 2012. 
Schichtel, B. A. and Husar, R. B.: Eastern North American transport climatology during high- and low-ozone days, Atmos. Environ., 35, 1029-1038, 2001.

Schwede, D., Pouliot, G. A., and Pierce, T.: Changes to the Biogenic Emissions Inventory System Version 3 (BEIS3), in: Proceedings of the 4th CMAS Models-3 Users' Conference, Chapel Hill, NC, 26-28 September 2005, available at: https://www. cmascenter.org/conference/2005/abstracts/2_7.pdf (last access: 8 March 2018), 2005.

Simon, H., Baker, K. R., and Phillips, S.: Compilation and interpretation of photochemical model performance statistics published between 2006 and 2012, Atmos. Environ., 61, 124-139, https://doi.org/10.1016/j.atmosenv.2012.07.012, 2012.

Skamarock, W. C. and Klemp, J. B.: A time-split nonhydrostatic atmospheric model for research and NWP applications, J. Comput. Phys., 227, 3465-3485, 2007.

Skamarock, W. C., Klemp, J. B., Duda, M. G., Fowler, L., Park, S.-H., and Ringler, T. D.: A Multi-scale Nonhydrostatic Atmospheric Model Using Centroidal Voronoi Tesselations and C-Grid Staggering, Mon. Weather Rev., 240, 3090-3105, https://doi.org/10.1175/MWR-D-11-00215.1, 2012.

Solazzo, E. and Galmarini, S.: Error apportionment for atmospheric chemistry-transport models - a new approach to model evaluation, Atmos. Chem. Phys., 16, 6263-6283, https://doi.org/10.5194/acp-16-6263-2016, 2016.

Solazzo, E., Bianconi, R., Vautard, R., Appel, K.W., Moran, M. D., Hogrefe, C., Bessagnet, B., Brandt, J., Christensen, J. H., Chemel, C., Coll, I., van der Gon, H. D., Ferreira, J., Forkel, R., Francis, X. V., Grell, G., Grossi, P., Hansen, A. B., Jericevic, A., Kraljevic, L., Prank, M., Riccio, A., Sartelet, K. N., Schaap, M., Silver, J. D., Sokhi, R. S., Vira, J., Werhahn, J., Wolke, R., Yarwood, G., Zhang, J., Rao, S. T., and Galmarini, S.: Model evaluation and ensemble modelling of surface-level ozone in Europe and North America in the context of AQMEII, Atmos. Environ., 53, 60-74, 2012a.

Solazzo, E., Bianconi, R., Pirovano, G., Matthias, V., Vautard, R., Moran, M. D., Appel, K. W., Bessagnet, B., Brandt, J., Christensen, J. H., Chemel, C., Coll, I., Ferreira, J., Forkel, R., Francis, X. V., Grell, G., Grossi, P., Hansen, A. B., Hogrefe, C., Miranda, A. I., Nopmongco, U., Prank, M., Sartelet, K. N., Schaap, M., Silver, J. D., Sokhi, R. S., Vira, J., Werhahn, J., Wolke, R., Yarwood, G., Zhang, J., Rao, S. T., and Galmarini, S.: Operational model evaluation for particulate matter in Europe and North America in the context of AQMEII, Atmos. Environ., 53, 75-92, 2012b.

Solazzo, E., Bianconi, R., Hogrefe, C., Curci, G., Tuccella, P., Alyuz, U., Balzarini, A., Baró, R., Bellasio, R., Bieser, J., Brandt, J., Christensen, J. H., Colette, A., Francis, X., Fraser, A., Vivanco, M. G., Jiménez-Guerrero, P., Im, U., Manders, A., Nopmongcol, U., Kitwiroon, N., Pirovano, G., Pozzoli, L., Prank, M., Sokhi, R. S., Unal, A., Yarwood, G., and Galmarini, S.: Evaluation and error apportionment of an ensemble of atmospheric chemistry transport modeling systems: multivariable temporal and spatial breakdown, Atmos. Chem. Phys., 17, 3001-3054, https://doi.org/10.5194/acp-17-3001-2017, 2017a.

Solazzo, E., Hogrefe, C., Colette, A., Garcia-Vivanco, M., and Galmarini, S.: Advanced error diagnostics of the CMAQ and Chimere modelling systems within the AQMEII3 model evaluation framework, Atmos. Chem. Phys., 17, 10435-10465, https://doi.org/10.5194/acp-17-10435-2017, 2017 b.
TF-HTAP (Task Force on Hemispheric Transport of Air Pollution): 2010 Final Assessment report, Part A: Ozone and particulate matter, available at: http://www.htap.org/publications/2010_ report/2010_Final_Report/HTAP2010PartA110407.pdf (last access: 8 March 2018), 2010.

Travis, K. R., Jacob, D. J., Fisher, J. A., Kim, P. S., Marais, E. A., Zhu, L., Yu, K., Miller, C. C., Yantosca, R. M., Sulprizio, M. P., Thompson, A. M., Wennberg, P. O., Crounse, J. D., St. Clair, J. M., Cohen, R. C., Laughner, J. L., Dibb, J. E., Hall, S. R., Ullmann, K., Wolfe, G. M., Pollack, I. B., Peischl, J., Neuman, J. A., and Zhou, X.: Why do models overestimate surface ozone in the Southeast United States?, Atmos. Chem. Phys., 16, 1356113577, https://doi.org/10.5194/acp-16-13561-2016, 2016.

Vukovich, F. M.: Regional-scale boundary-layer ozone variations in the eastern United States and their association with meteorological variations, Atmos. Environ., 29, 2259-2273, 1995.

van der Werf, G. R., Randerson, J. T., Giglio, L., Collatz, G. J., Kasibhatla, P. S., and Arellano Jr., A. F.: Interannual variability in global biomass burning emissions from 1997 to 2004, Atmos. Chem. Phys., 6, 3423-3441, https://doi.org/10.5194/acp-6-34232006, 2006.

Vautard, R., Beekmann, M., Roux, J., and Gombert, D.: Validation of a hybrid forecasting system for the ozone concentrations over the Paris area, Atmos. Environ., 35, 2449-2461, 2001.

Vukovich, J. and Pierce, T.: The Implementation of BEIS3 within the SMOKE Modeling Framework, in: Proceedings of the 11th International Emissions Inventory Conference, Atlanta, Georgia, available at: www.epa.gov/ttn/chief/conference/ei11/modeling/ vukovich.pdf (last access: 8 March 2018), 2002.

Wiedinmyer, C., Akagi, S. K., Yokelson, R. J., Emmons, L. K., AlSaadi, J. A., Orlando, J. J., and Soja, A. J.: The Fire INventory from NCAR (FINN): a high resolution global model to estimate the emissions from open burning, Geosci. Model Dev., 4, 625641, https://doi.org/10.5194/gmd-4-625-2011, 2011.

Xing, J., Mathur, R., Pleim, J., Hogrefe, C., Gan, C.-M., Wong, D. C., Wei, C., Gilliam, R., and Pouliot, G.: Observations and modeling of air quality trends over 1990-2010 across the Northern Hemisphere: China, the United States and Europe, Atmos. Chem. Phys., 15, 2723-2747, https://doi.org/10.5194/acp-152723-2015, 2015a.

Xing, J., Mathur, R., Pleim, J., Hogrefe, C., Gan, C.-M., Wong, D. C., and Wei, C.: Can a coupled meteorology-chemistry model reproduce the historical trend in aerosol direct radiative effects over the Northern Hemisphere?, Atmos. Chem. Phys., 15, 999710018, https://doi.org/10.5194/acp-15-9997-2015, 2015b.

Zhang, L., Jacob, D. J., Yue, X., Downey, N. V., Wood, D. A., and Blewitt, D.: Sources contributing to background surface ozone in the US Intermountain West, Atmos. Chem. Phys., 14, 52955309, https://doi.org/10.5194/acp-14-5295-2014, 2014. 